\title{
Brain natriuretic peptide in pulmonary arterial hypertension: biomarker and potential therapeutic agent
}

\author{
This article was published in the following Dove Press journal: \\ Drug Design, Development and Therapy \\ 27 November 2009 \\ Number of times this article has been viewed
}

\author{
Brian Casserly \\ James R Klinger \\ Division of Pulmonary and Critical \\ Care Medicine, The Memorial Hospital \\ of Rhode Island, Pawtucket, RI, Rhode \\ Island Hospital, Providence, RI, Alpert \\ Medical School of Brown University, \\ Providence, RI, USA
}

\begin{abstract}
B-type natriuretic peptide (BNP) is a member of the natriuretic peptide family, a group of widely distributed, but evolutionarily conserved, polypeptide mediators that exert myriad cardiovascular effects. BNP is a potent vasodilator with mitogenic, hypertrophic and pro-inflammatory properties that is upregulated in pulmonary hypertensive diseases. Circulating levels of BNP correlate with mean pulmonary arterial pressure (mPAP) and pulmonary vascular resistance (PVR) in patients with pulmonary arterial hypertension (PAH). Elevated plasma BNP levels are associated with increased mortality in patients with PAH and a fall in BNP levels after therapy is associated with improved survival. These findings have important clinical implications in that a noninvasive blood test may be used to identify PAH patients at high-risk of decompensation and to guide pulmonary vasodilator therapy. BNP also has several biologic effects that could be beneficial to patients with PAH. However, lack of a convenient method for achieving sustained increases in circulating BNP levels has impeded the development of BNP as a therapy for treating pulmonary hypertension. New technologies that allow transdermal or oral administration of the natriuretic peptides have the potential to greatly accelerate research into therapeutic use of BNP for cor pulmonale and pulmonary vascular diseases. This review will examine the basic science and clinical research that has led to our understanding of the role of BNP in cardiovascular physiology, its use as a biomarker of right ventricular function and its therapeutic potential for managing patients with pulmonary vascular disease.
\end{abstract}

Keywords: brain natriuretic peptide, pulmonary artery hypertension, biomarker, therapeutic agent

\section{Introduction}

Pulmonary arterial hypertension (PAH) is a progressive vasculopathy characterized by extensive remodeling of the pulmonary circulation that results in narrowing of the arterial lumen and impaired flow-mediated vasodilation. The marked increase in pulmonary vascular resistance limits the rate at which the right ventricle can pump blood through the lungs, causing shortness of breath and reduced functional capacity. The disease can occur at any age, but frequently affects young adults in the third or fourth decade of life who are otherwise healthy. Until recently, there were no specific therapies available to treat this disease and most patients progressed to right ventricular failure and death within 2 to 5 years of diagnosis. ${ }^{1}$ In 1995, intravenous epoprostenol became the first drug approved for the treatment of PAH in the United States. Since that time 6 more medications have been approved and several more await consideration by the FDA. These medications have improved survival and exercise capacity, but none have been able to achieve a cure and the majority of patients continue to progress to

submit your manuscript $\mid$ www.dovepress.com 
right ventricular failure, albeit at a slower pace. The lack of a cure and the severity with which PAH strikes has generated considerable interest in furthering the understanding of the pathogenesis of this disease and the development of new diagnostic and therapeutic modalities to manage it.

Brain natriuretic peptide (BNP) is one of several members of the natriuretic peptide family that are widely distributed, but evolutionarily conserved throughout the animal kingdom. The natriuretic peptides play important roles in cardiovascular homeostasis including regulation of vascular tone, blood volume, endothelial permeability, and cardiac hypertrophy. Cardiac BNP expression is markedly upregulated in response to ventricular hypertrophy or overload and circulating BNP levels can increase by 1 to 2 orders of magnitude. There is increasing evidence that BNP may be a useful marker for right ventricular dysfunction and predict outcome in patients with PAH. As such, plasma BNP may help guide clinical decision making in patients with newly diagnosed $\mathrm{PAH}$ and help gauge response to treatment. BNP is also a pulmonary vasodilator and anti-hypertrophic agent and thus, may have therapeutic potential to inhibit pulmonary vascular remodeling and maladaptive increases in right ventricular mass.

This paper examines the role of BNP in assessing the severity of pulmonary vascular disease and its potential as a therapeutic agent for the treatment of PAH. The synthesis, secretion and biologic properties of BNP, relevant to its role in mediating pulmonary vascular tone, is discussed first followed by a review of its inhibitory effects on pulmonary vascular remodeling, cardiac hypertrophy and endothelial cell apoptosis. Finally, potential therapeutic applications for the treatment of PAH and right heart failure are presented.

\section{Pulmonary arterial hypertension}

Pulmonary hypertension $(\mathrm{PH})$ refers to a variety of conditions in which pulmonary arterial pressure (PAP) is elevated above normal. Mean pulmonary arterial pressure (mPAP) in a healthy adult at rest averages about 14 to $17 \mathrm{mmHg}$. Pulmonary hypertension is defined as a resting mPAP $>25 \mathrm{mmHg}$ or a $\mathrm{mPAP}>30 \mathrm{mmHg}$ during exercise and a pulmonary capillary wedge pressure $(\mathrm{PCWP})<15 \mathrm{mmHg}$. Providing that cardiac output is not elevated, this results in a pulmonary vascular resistance $(\mathrm{PVR})>3$ Wood units. Most patients with $\mathrm{PAH}$ have a mPAP that is considerably higher, however. In fact, the mean mPAP of over $600 \mathrm{PAH}$ patients in the French pulmonary hypertension registry was $55 \pm 15 \mathrm{mmHg}$, more than double the cut off level of $25 \mathrm{mmHg} .{ }^{2}$ The most common causes of elevated PAP are chronic lung and left sided heart disease. Elevated PAP in these conditions occurs as the result of hypoxia, loss of the pulmonary vascular bed or elevated pulmonary venous pressure due to impaired left sided heart function. Rarely, PH occurs as the result of abnormal constriction and remodeling of the pulmonary arteries in the absence of any other underlying cardiopulmonary disease. This type of $\mathrm{PH}$ represents a true pulmonary artery vasculopathy, described by Dresdale et al in 1951 as primary pulmonary hypertension. ${ }^{2}$ Since then, the term secondary $\mathrm{PH}$ has been used to describe $\mathrm{PH}$ associated with heart and lung disease or other identifiable causes of increased pulmonary vascular resistance. Major advances in our understanding of pulmonary vascular disease led to new terminology proposed during the 4th World Symposium on PH held in 2008 at Dana Point, California that organizes pulmonary hypertension into 5 groups to reflect the major underlying etiologies and sites of injury (Table 1). ${ }^{3}$

PAH is a disease that is characterized by hypertrophy and proliferation of pulmonary vascular smooth muscle and subsequent thickening of the medial wall of mid sized pulmonary arteries and the muscularization of more peripheral, normally non-muscularized vessels. ${ }^{4}$ Marked proliferation of endothelial cells in distal pulmonary arteries is also evident and in some areas causes near obliteration of the vascular lumen with evidence of recanulized channels (plexiform lesions). These changes in both the smooth muscle and endothelial layers substantially reduce the cross sectional area of the pulmonary vascular tree. ${ }^{5}$ At the same time, pulmonary vascular tone may be increased and the ability of the pulmonary circulation to dilate or recruit underutilized vessels in response to increased flow is reduced. ${ }^{6}$ As remodeling of the pulmonary vascular bed progresses, PVR rises, increasing right ventricular afterload and leading to decreased functional capacity and eventually right ventricular failure. ${ }^{7}$

The diagnosis and treatment of PAH is hampered by difficulty in obtaining accurate measurements of PAP. Unlike the systemic circulation where intravascular pressure is easily measured by syphgmometry, there is no accurate, readily available noninvasive test for measuring PAP. Right heart catheterization (RHC) provides the direct measurement of PAP and is vital in the appropriate diagnosis and evaluation of unexplained $\mathrm{PH}$, but it is invasive and expensive and not amenable to repeated measurements that are necessary to monitor disease progression. As a result, the clinician must rely on a combination of indirect assessments of PAP and cardiac output such as transthoracic echocardiography, 6-minute walking distance, and WHO functional class. A simple noninvasive, but objective measure of right 
Table I Updated clinical classification of pulmonary hypertension (Dana Point 2008) ${ }^{3}$

I. Pulmonary arterial hypertension (PAH)

I.I. Idiopathic PAH

1.2. Heritable

I.2.1. BMPR2

I.2.2. ALKI, endoglin (with or without hereditary hemorrhagic telangiectasia)

1.2.3. Unknown

1.3. Drug- and toxin-induced

1.4. Associated with

I.4. I. Connective tissue diseases

I.4.2. HIV infection

1.4.3. Portal hypertension

1.4.4. Congenital heart diseases

1.4.5. Schistosomiasis

1.4.6. Chronic hemolytic anemia

I.5 Persistent pulmonary hypertension of the newborn

I. Pulmonary Veno-Occlusive Disease (PVOD) and/or Pulmonary

Capillary Hemangiomatosis ( $\mathrm{PCH}$ )

2. Pulmonary hypertension owing to left heart disease

2.I. Systolic dysfunction

2.2. Diastolic dysfunction

2.3. Valvular disease

3. Pulmonary hypertension owing to lung diseases and/or hypoxia

3.I. Chronic obstructive pulmonary disease

3.2. Interstitial lung disease

3.3. Other pulmonary diseases with mixed restrictive and obstructive pattern

3.4. Sleep-disordered breathing

3.5. Alveolar hypoventilation disorders

3.6. Chronic exposure to high altitude

3.7. Developmental abnormalities

4. Chronic thromboembolic pulmonary hypertension (CTEPH)

5. Pulmonary hypertension with unclear multifactorial mechanisms

5. I. Hematologic disorders: myeloproliferative disorders, splenectomy

5.2. Systemic disorders: sarcoidosis, pulmonary Langerhans cell histiocytosis: lymphangioleiomyomatosis, neurofibromatosis, vasculitis

5.3. Metabolic disorders: glycogen storage disease, Gaucher disease, thyroid disorders

5.4. Others: tumoral obstruction, fibrosing mediastinitis, chronic renal failure on dialysis

Abbreviations: ALKI, activin receptor-like kinase type I; BMPR2, bone morphogenetic protein receptor type.

ventricular afterload would contribute significantly to the management of PAH patients. Biomarkers that correlate with PAP and/or right sided filling pressures would allow the practitioner insight into how a patient's disease is progressing and allow the physician to evaluate the effect of pulmonary vasodilator therapy. Plasma BNP levels rise in response to right as well as left atrial or ventricular overload and may be an important tool for assessing right ventricular performance in PAH.

The treatment of PAH has grown considerably in the last decade. Presently, 7 different medications belonging to 3 distinct pharmaceutical classes are available for the management of PAH. However, in the great majority of patients, none of these treatments are capable of restoring normal pulmonary hemodynamics and exercise capacity and have limited ability to improve right heart function. Furthermore, all 3 classes focus primarily on vasodilation or remodeling of the pulmonary circulation. Additional therapies are needed that aid the right ventricle in maintaining adequate systolic function and inhibit maladaptive hypertrophic changes in response to persistent elevation in afterload.

\section{Brain natriuretic peptide $B N P$ release}

Human BNP is a 32-amino acid polypeptide secreted predominantly by the cardiac atria and ventricles. BNP is synthesized as a preprohormone of 134 residues that is cleaved to yield a 108 -amino-acid prohormone (proBNP1-108). The prohormone is subsequently cleaved by an unknown protease to an inactive 76-residue aminoterminal (NT) fragment known as NT-BNP and the 32 aminoacid, carboxyl-terminal 32 fragment that is the biologically active peptide..$^{8-12}$ The size of the final, fully processed BNP fragment varies between species. Human, pig, and dog BNP contain 32 amino acids, ${ }^{13,14}$ whereas rat and mouse BNP is a 45 amino acid peptide. ${ }^{8,10,11,15-17}$ Compared to the sequence homology of atrial natriuretic peptide (ANP) and C-type natriuretic peptide $(\mathrm{CNP})$ that are tightly conserved, the sequence homology of BNP differs across species both in size and amino acid sequence ${ }^{17,18}$ (Figure 2). This sequence variability may explain, in part, the variations of BNP biological activity in different species.

Although originally discovered in porcine brain, human BNP is expressed primarily in the cardiac atria and ventricles. The tissue concentration of BNP in the ventricle constitutes only about $1 \%$ of the atrium. However, the total BNP mRNA content is almost 3 -fold higher in the ventricle.$^{19}$ The majority of circulating BNP $(>60 \%)$ is released from ventricular tissues. ${ }^{19-22}$ This is in distinction from ANP, the great majority of which is synthesized and released by the cardiac atria. ${ }^{19}$ These findings have prompted some investigators to suggest that ANP and BNP make up a dual cardiac peptide system with ANP the primary atrial peptide and BNP the primary ventricular peptide. In fact, some investigators have suggested 


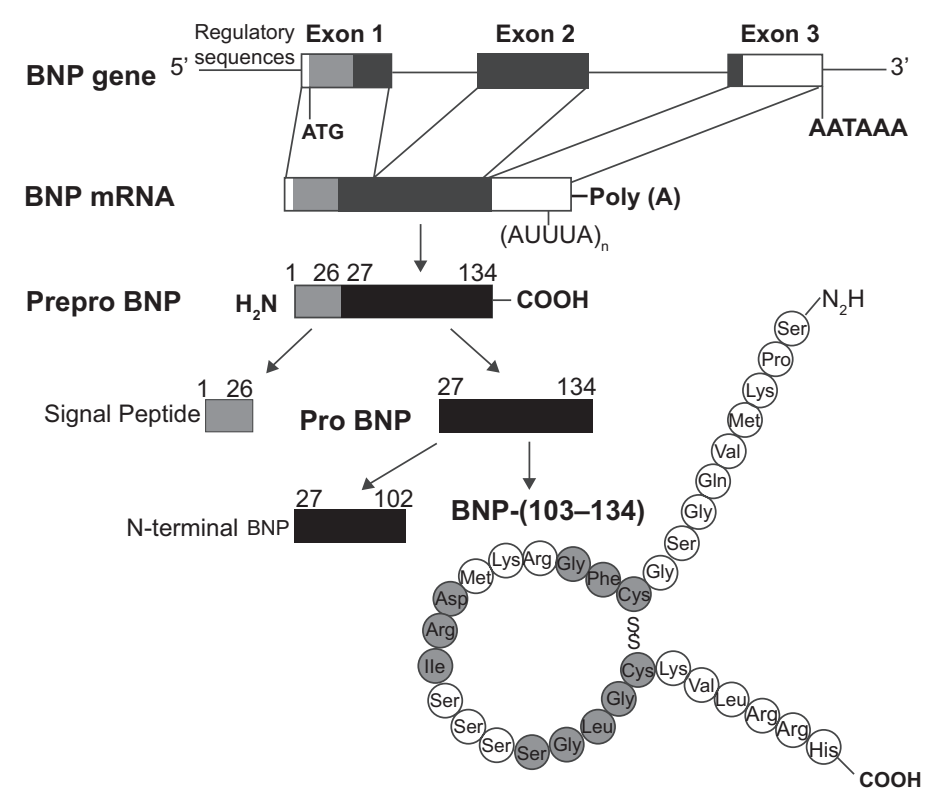

Figure I Structure of the gene and the biosynthetic pathway of human brain natriuretic peptide (BNP). The major storage form of BNP in the heart is the cleaved mature peptide, although in atrial tissue also prohormones may be stored. Reproduced with permission from Barr CS, Rhodes P, Struthers AD. C-type natriuretic peptide. Peptides. 1996; 17(7): 1243-1251. ${ }^{197}$ Copyright (C) 1996 Elsevier.

that BNP be renamed to ventricular natriuretic peptide to denote its greater importance in the cardiovascular system and to distinguish it from ANP.

Both atrial and ventricular BNP expression is induced within $1 \mathrm{hr}$ of myocardial stretch from increases in venous volume or arterial pressure. ${ }^{23,24}$ Other stimuli that induce cardiac BNP secretion include hypoxia, ischemia, and states of nephrosis and cirrhosis that are associated with an increase in central blood volume. ${ }^{25-27}$ Several neuroendocrine mechanisms also mediate cardiac BNP release. ${ }^{28,29}$ For example, $\alpha$-adrenergic stimulation with phenylephrine results in increases in both BNP gene expression and BNP secretion, whereas myocardial stretch and endothelin-1 (ET-1) induce a marked increase in BNP gene expression alone. ${ }^{29,30}$

Atrial myocytes store pre-synthesized ANP and BNP in secretory granules and release them via a regulated pathway. ${ }^{31}$ Unlike ANP, however, most studies in normal subjects show no significant change in BNP levels in response to exercise..$^{32-35}$ In patients with cardiac disease such as ischemia, hypertension or heart transplant recipients, exercise does induce a significant increase in BNP secretion. ${ }^{32-37}$ These findings suggest that only under pathologic conditions is atrial BNP secreted during exercise-induced heart stress via a regulatory pathway in quantities sufficient to increase circulating levels. Ventricular myocytes also synthesize and secrete both peptides, but through a constitutive pathway. ${ }^{20}$ Hence, it is possible that BNP is secreted by ventricular tissue during exercise. Most of the immediate release of BNP likely derives from atrial stores followed later by gene transcription and new protein synthesis from atrial and ventricular sources. BNP mRNA has a faster turnover rate than ANP due to the presence of mRNA-destabilizing AUUUA repeats in the 3'-untranslated region. This allows the synthesis and secretion of BNP in the ventricles to be closely controlled by mRNA levels according to changing amounts of load on the myocardium. The 5'-untranslated region of the gene possesses shear stress response elements and activation of MAPK and nuclear factor $\kappa \mathrm{B}(\mathrm{NF}-\kappa \mathrm{B})$ is thought to be important in upregulating expression. ${ }^{38}$ The nuclear transcription factor, GATA 4, plays a dominant role in regulating this process. ${ }^{39-41}$ The ability of BNP to be secreted from the heart in response to neurohormonal as well as hemodynamic stimuli and the rapid induction of BNP gene expression in response to ventricular strain make it a robust biomarker of cardiac stress and facilitates its use as a clinical tool.

\section{BNP receptors}

The diverse biological effects of BNP are mediated primarily by a membrane-bound particulate guanylyl cyclase receptor called natriuretic peptide receptor-A (NPR-A). NPR-A is widely expressed in the cardiovascular system including the cardiac atria and the ventricles as well as the aorta and peripheral vasculature, lungs, kidney, skin, platelets, and presynaptic sympathetic fibers. ${ }^{42-47}$ NPR-A has much higher affinity for ANP and BNP, than for CNP, but BNP is approximately 10-fold less potent than ANP in 

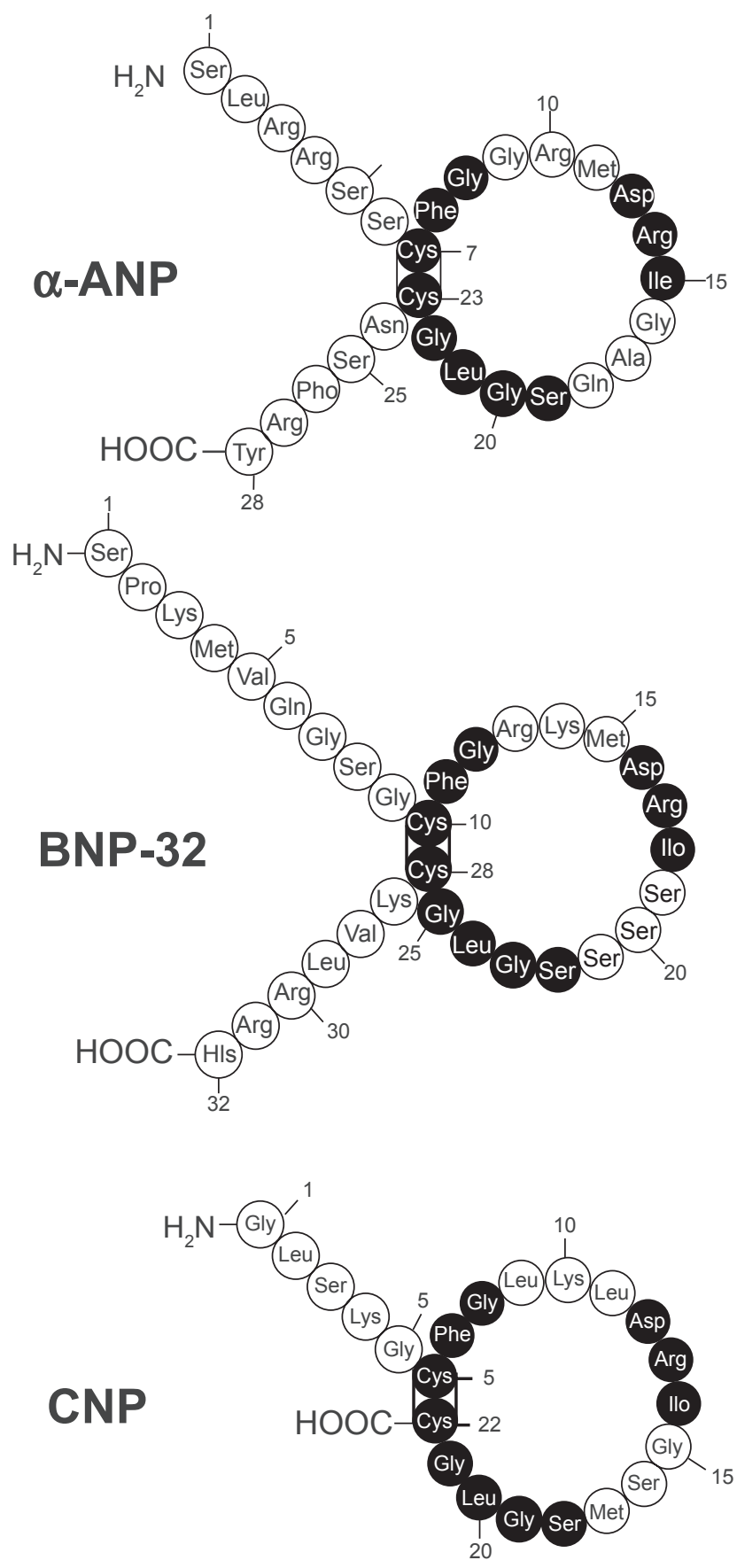

Figure 2 Amino acid structure of the 3 natriuretic peptides, atrial, brain and c-type natriuretic peptide (ANP, BNP, CNP). All 3 peptides share a similar 17 amino acid loop. Shaded circles represent amino acid sequence that is identical in each peptide. Reproduced with permission from Barr CS, Rhodes P, Struthers AD. C-type natriuretic peptide. Peptides. 1996;17(7): 1243-1251. ${ }^{197}$ Copyright (C) 1996 Elsevier.

generating particulate cGMP. ${ }^{48-50}$ Another membrane bound guanylyl-cyclase linked receptor, NPR-B, demonstrates high affinity for CNP and much lower affinity for ANP and BNP. ${ }^{49,51}$ Both NPR-A and NPR-B function as particulate guanylyl cyclases ${ }^{43,52}$ distinct from the cytoplastic soluble gaunylyl cyclase stimulated by nitric oxide (NO). ${ }^{53}$
Ligand binding to NPR-A or NPR-B activates the intracellular guanalyl cyclase domain of the receptor and catalyzes the synthesis of cGMP. There are three known proteins that bind cGMP with high affinity and act as downstream targets: cGMP-dependent protein kinase (PKG), cGMP binding phosphodiesterases (PDEs), and cyclic nucleotide-gated ion channels. PKG appears to be the principal intracellular mediator of cGMP signals. ${ }^{54-58}$ Natriuretic peptide-induced elevation of intracellular cGMP causes a binding-dependent activation of PKG leading to the catalytic transfer of phosphate from ATP to a serine or threonine residue of target proteins. The phosphorylated proteins then determine the translation of the extracellular stimulus into a specific biological function. ${ }^{59}$

Cyclic nucleotides such as cGMP and cAMP are metabolized by a family of phosphodiesterases (PDE). ${ }^{60-63}$ PDE-1, -2, -3, -10, and -11 degrade both cGMP and cAMP; PDE-4, -7, and -8 specifically hydrolyze cAMP; whereas PDE-5, -6 , and -9 are highly selective for cGMP. ${ }^{64}$ In vascular tissue, PDE-3 and -4 are responsible for most of the degradation of cAMP and PDE-5 is the major metabolic enzyme for cGMP. Despite the relative selectivity of PDE isoforms, both cAMP and cGMP can act as substrate for the other's primary PDE and thereby impede its metabolism. There is clear evidence that this interaction between cyclic nucleotides and PDEs allows for crosstalk and integration between different pathways. ${ }^{60}$ PDE- 5 is expressed in most vascular smooth muscle, is found in high concentration in the lung, and is increased in the lungs in experimental models of pulmonary hypertension. ${ }^{65,66} \mathrm{PDE}-\mathrm{I}$ in heart, lungs, brain, and smooth muscle is activated by binding of $\mathrm{Ca}^{2+}$-calmodulin to cause a decrease in cyclic nucleotide (cGMP or cAMP) concentration. Some PDEs are regulated allosterically by cGMP. For instance, in addition to its catalytic domain, PDE-5 has additional binding sites for both cGMP and PKG that serve to stabilize the enzyme and enhance cGMP metabolism resulting in a feed-forward mechanism

\section{BNP metabolism and clearance}

Circulating natriuretic peptides are removed or metabolized via two major routes. One involves binding of the natriuretic peptide to natriuretic peptide receptor-C (NPR-C). NPR-C has an extracellular domain similar to that of NPR-A and NPR-B, but no intracellular guanylyl cyclase domain. Binding to the receptor is followed by endocytosis and lysosomal degradation, ${ }^{67}$ NPR-C has high affinity for all natriuretic peptides with a rank order of ANP $\geq \mathrm{CNP}>\mathrm{BNP}$ in both humans and rats $^{51,68}$ and has been proposed to function 
primarily as a clearance receptor, ${ }^{46,69}$ although other biologic effects have been described. ${ }^{42}$

The second mode of metabolism is peptide cleavage and inactivation by neutral endopeptidase 24.11 (NEP). ${ }^{70}$ This membrane bound zinc metalloproteinase is found on the luminal surface of endothelial cells and is particularly concentrated at the brush border membranes in the proximal tubule of the kidney. NEP inactivates and degrades both ANP and BNP, ${ }^{70,71}$ by opening their ring structures. ${ }^{72}$ The relative importance of the two clearance mechanisms is controversial, but it has been shown that in chronic heart failure, the clearance receptor NPR-C may play a lesser role than NEP in natriuretic peptide metabolism. ${ }^{73}$ Renal excretion of the peptides has also been described, ${ }^{74}$ but probably plays a minor role in regulating circulating concentrations of natriuretic peptides.

The circulating BNP level measured at any given time point is the result of the balance between BNP secretion and degradation. BNP has a plasma half-life of about 20 minutes, which is substantially longer than the 4 minute half-life reported for ANP. ${ }^{75}$ The longer half-life may be the result of more resistance to degradation by NEPs and less avid binding to NPR-C than ANP. ${ }^{76}$ Healthy individuals have plasma BNP concentrations around $1 \mathrm{fmol} / \mathrm{ml}(3.5 \mathrm{pg} / \mathrm{ml})$ or approximately one-tenth that of ANP. ${ }^{77}$ However, plasma BNP levels in congestive heart failure patients can be 200- to 300-fold higher. The enormous range of plasma BNP concentrations between healthy subjects and patients with heart failure and the rapid induction of BNP expression in response to acute overload or ischemia make it well suited to serve as an indicator of elevated myocardial loading and cardiac stress. ${ }^{78,79}$ The amino terminal fragment of proBNP (NT-proBNP) is less susceptible to degradation by NEP and is not cleared by NPR-C. As such, it may represent a more reliable indicator of cardiac BNP expression and secretion than circulating BNP levels. In fact, some studies suggest that plasma NT-proBNP levels may be a more sensitive and specific marker of cardiovascular disease than BNP. ${ }^{80,81} \mathrm{In}$ patients, with left ventricular (LV) dysfunction NT-proBNP levels are up to 10 times higher than BNP. ${ }^{82}$ Unfortunately, NT-proBNP assays are not readily available in most clinical laboratories. A number of factors have been associated with higher BNP levels in addition to ventricular wall stress. Both BNP and NT-proBNP increase with age independent of the increased incidence of diastolic dysfunction..$^{83}$ BNP and NT-proBNP levels are also higher in women than men at any age. ${ }^{84}$ The association between BNP and renal function is complex. Patients with chronic renal disease tend to have higher atrial pressure, systemic pressure, and ventricular mass, all of which would be expected to increase BNP synthesis and secretion. As mentioned previously, renal excretion of BNP has been described, but alterations in circulating levels in patients with renal disease are more likely related to decreased clearance by NPR-C and endopeptidases. NT-proBNP, in contrast, is predominantly excreted by the kidney, although plasma NT-proBNP, appears to maintain it's clinical utility even in the presence of renal dysfunction. ${ }^{85,86}$

\section{Use of BNP as a biomarker in $\mathbf{P H}$ Pulmonary arterial pressure and RV strain}

As in systemic hypertension, PAH is a hemodynamic diagnosis. The clinical manifestations of PAH and RV failure are non-specific, and are usually not evident on exam or general diagnostic tests such as chest roentgenogram and electrocardiogram until the disease is fairly advanced. Circulating levels of ANP and BNP correlate with mPAP, ${ }^{87}$ but elevations in BNP levels are usually not seen until PAP is high enough to cause right ventricular strain. Therefore, BNP has limited diagnostic value as a screening tool for excluding PAH in populations at low risk for the disease. In select patient groups however, where the risk of PAH is substantially increased, such as those with connective tissue disease, portal hypertension, congenital systemic to pulmonary shunts, or a family history of IPAH, elevated BNP may help identify patients in whom further testing is warranted. For example, BNP may prove useful as a screening test for PAH in systemic sclerosis, where the prevalence of $\mathrm{PH}$ has been reported to be $12 \%$ to $35 \%$ and where PAH treatment has been shown to be beneficial. ${ }^{88-92}$ In 2003, Allanore et al obtained plasma NT-proBNP levels and echocardiographic estimates of peak PAP in 40 consecutive patients hospitalized for follow-up care of scleroderma (limited or diffuse disease). ${ }^{93}$ All patients were without symptoms of heart failure, had normal LV ejection fraction, and a creatinine clearance $>58 \mathrm{~mL} / \mathrm{min}$. At baseline, 10 patients $(25 \%)$ were found to have PAH as defined by a peak right ventricular systolic pressure (RVSP) $>40 \mathrm{mmHg}$. Thirteen patients had high NT-proBNP values (adjusted for age), including all 10 patients classified as PAH by TTE. There was a moderate correlation between peak RVSP and NT-proBNP level $(\mathrm{r}=0.44, P=0.006)$. A high NT-proBNP concentration (cutoff values supplied by the manufacturer and defined as above the 97th percentile) identified $\mathrm{PH}$ with a sensitivity of $90 \%$, specificity of $90 \%$, positive predictive value of $69 \%$, and negative predictive value of $96 \%$. Although the sensitivity and specificity of transthoracic echo 
for detecting $\mathrm{PH}$ is only about $90 \%$ and $75 \%$ respectively, subsequent studies using right heart catheterization to define PAH have obtained similar results. ${ }^{94}$ Mukerjee et al identified found PAH by RHC in 23 of 49 patients with SSc. ${ }^{95}$ The mean value of NT-proBNP in patients with $\mathrm{PAH}$ was $3365 \pm 1095) \mathrm{pg} / \mathrm{mL}$ compared to $347 \pm 174 \mathrm{pg} / \mathrm{mL}$ for patients without $\mathrm{PAH}$. There was a statistically significant correlation $(P<0.05)$ between NT-proBNP values and (i) $\mathrm{mPAP}(\mathrm{r}=0.53)$, (ii) right ventricular end diastolic pressure $(r=0.59)$ and (iii) PVR $(r=0.49)$. Receiver operator characteristic curve analysis showed that a cut-off value of 395.34 $\mathrm{pg} / \mathrm{mL}$ had a sensitivity of 0.69 and specificity of 1.0 . The same group performed a larger study to assess prospectively the specificity of $395 \mathrm{pg} / \mathrm{mL}$ in a larger population and to evaluate the prognostic value of NT-proBNP in a homogenous group of patients with scleroderma associated PAH (SSc-PAH). ${ }^{94}$ The study population included 68 individuals with PAH mPAP $>25 \mathrm{mmHg}$ and PCWP $<15 \mathrm{mmHg}$ and 41 individuals without $\mathrm{PAH}$. The patients without PAH had a lower mean NT-proBNP level than those with SSc-PAH baseline NT-proBNP levels were correlated positively with mPAP $(\mathrm{r}=0.62 ; P<0.0001)$, PVR $(\mathrm{r}=0.81$; $P<0.0001)$, and inversely with 6 minute walking distance (6MWD) $(\mathrm{r}=-0.46 ; P<0.0001)$. At an NT-proBNP level of $395 \mathrm{pg} / \mathrm{mL}$, the sensitivity and specificity for predicting the presence of SSc-PAH were 56\% and 95\% respectively. Thus NT-proBNP estimation in systemic sclerosis-related PAH is a potentially useful diagnostic tool. Similarly, subjects with lung fibrosis and elevated BNP levels $(n=20)$ had significantly higher PAP than those with normal BNP levels (mean pulmonary arterial pressure $(40.85 \pm 3.2 \mathrm{mmHg}$ vs $23.42 \pm 1.44 \mathrm{mmHg},(P<0.001) .{ }^{96}$

Although TTE is the most commonly used test to diagnose or exclude $\mathrm{PH}$, its specificity is low in early disease. ${ }^{95}$ For example, a RVSP > $40 \mathrm{mmHg}$ commonly used cut off level to separate normal from elevated PAP has been found in 6\% of individuals older than 50 years of age and in $5 \%$ of patients with a body mass index $>30 \mathrm{~kg} / \mathrm{m}^{2}$ in the absence of pulmonary hypertension. ${ }^{97}$ In patients such as these, an elevated plasma BNP level may improve the diagnostic accuracy of TTE in screening for PAH. Two recent studies have demonstrated the potential utility of exercise echocardiography in identifying individuals at risk for future development of $\mathrm{PH}$ in at risk populations. ${ }^{98,99}$ It is interesting to speculate whether increased levels of BNP during exercise would improve the predictive accuracy of this emerging technology.

In addition to PAP, plasma BNP levels are a reliable marker of right heart strain, which is a significant predictor of morbidity and mortality in PAH and other forms of pulmonary disease causing pulmonary hypertension. ${ }^{100,101}$ Elevated BNP is not specific for right or left sided heart disease, but in the absence of left sided heart disease, may prove to be useful adjunct to echocardiography in evaluating right heart stress. In patients with right ventricular pressure overload associated with idiopathic PAH or CTEPH, BNP levels were significantly higher than in controls $(294 \pm 72 \mathrm{pg} / \mathrm{mL}$ versus $48 \pm 14 \mathrm{pg} / \mathrm{mL}$ $(P<0.05) .{ }^{100}$ In this study, BNP levels correlated with, right ventricular end diastolic pressure $(r=0.76)$ as well as mPAP $(\mathrm{r}=0.73)$ and total pulmonary resistance $(\mathrm{TPR})(\mathrm{r}=0.79)$. Long-term treatment with either prostacyclin or prostaglandin E reduced TPR (from 23 to 15 Wood units) and cut plasma BNP by more than half ( $315 \pm 120$ to $144 \pm 54 \mathrm{pg} / \mathrm{mL}$ ). BNP levels have also been shown to be higher in acute pulmonary embolism and to fall following thromboendarterectomy in patients with CTEPH. ${ }^{100,102}$ Conversely, right ventricular dilation is exceedingly uncommon in acute $\mathrm{PE}$ when plasma troponin and BNP levels are normal. ${ }^{103}$ Souza et al demonstrated a close correlation between PVR and NT-proBNP ( $\mathrm{r}=0.80, P<0.001)$ in 42 patients with IPAH. ${ }^{104} \mathrm{BNP}$ levels also correlate with functional capacity in PAH. In one study, BNP levels were inversely correlated with 6MWD $(\mathrm{r}=-0.70 ; P<0.001)$ and peak $\mathrm{VO}_{2}(\mathrm{r}=-0.61 ; P<0.01)$, and positive correlation with WHO functional class $(\mathrm{r}=0.79$; $P<0.001)$ in 42 patients with IPAH. ${ }^{96}$

\section{Survival and response to therapy}

Plasma BNP levels have been shown to have significant prognostic capabilities in patients with PAH. ${ }^{105}$ One study measured plasma BNP levels in 60 patients with IPAH at initial right heart catheterization and compared the prognostic significance of baseline and follow-up BNP levels with clinical, echocardiographic, and hemodynamic variables. Patients with renal insufficiency were excluded. Measurements were repeated in 53 patients at 3 months. Plasma BNP was increased at baseline and correlated positively with New York Heart Association (NYHA) functional class (Figure 3), mPAP, mean RAP, and TPR, and correlated negatively with cardiac output. Mean follow-up averaged 24 months, during which time 18 patients died of cardiopulmonary causes. Among the noninvasive baseline parameters studied, only plasma BNP was an independent predictor of mortality by multivariate analysis. Kaplan-Meier analysis demonstrated that follow-up BNP provided a more distinct separation of survival curves than did baseline BNP measurement (Figure 3). Survival was markedly improved in those patients with a follow-up BNP level below $180 \mathrm{pg} / \mathrm{mL}$. 
A

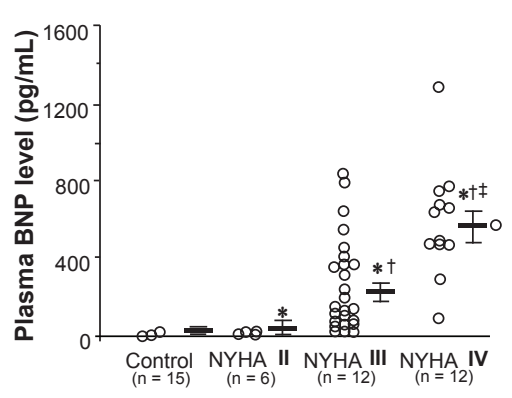

C

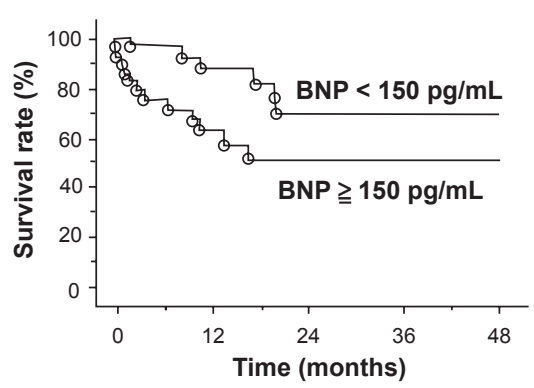

B
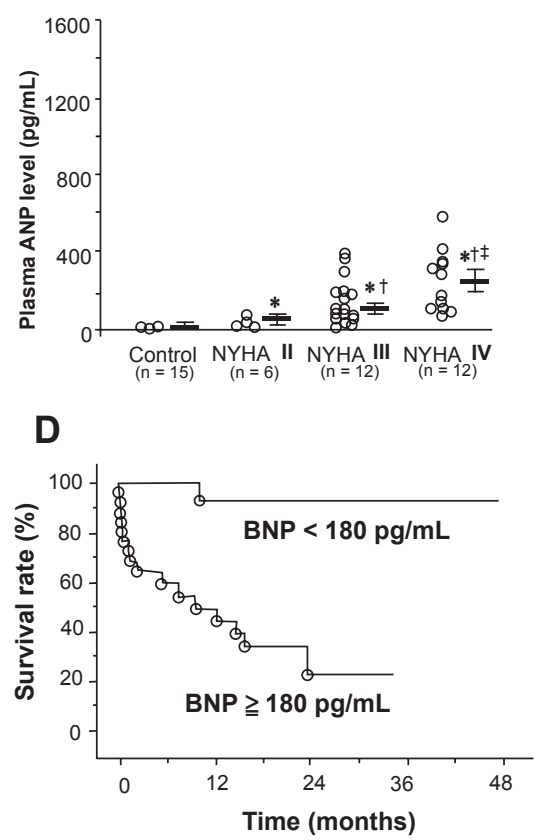

Figure 3 A) and B) Correlation between plasma brain natriuretic peptide (BNP) and atrial natriuretic peptide (ANP) and New York Heart Association (NYHA) functional class in patients with pulmonary arterial hypertension. C) Effect of plasma BNP levels at time of diagnosis on survival in patients with pulmonary arterial hypertension. D) Effect of plasma BNP levels after treatment on survival in the same patients. Reproduced with permission from Nagaya $\mathrm{N}$, et al. Plasma brain natriuretic peptide as a prognostic indicator in patients with primary pulmonary hypertension. Circulation. 2000;102(8): 865-870. ${ }^{105}$ Copyright (C) 2002 Elsevier.

In fact, receiver operating characteristic analysis suggested that baseline BNP was at least equal to mPAP and superior to $\mathrm{CO}$ in predicting mortality. These findings were substantiated by Fijalkowska et al who demonstrated in their 36 IPAH patients that a serum NT-proBNP level of $\geq 1400 \mathrm{pg} / \mathrm{mL}$ identified patient with a poor long term prognosis estimated by Kaplan-Meier cumulative survival curves. ${ }^{106}$

Plasma NT-proBNP levels have also been shown to predict survival in patients with $\mathrm{PH}$ (Figure 4). The use of NT-proBNP to predict survival was assessed in 68 patients with $\mathrm{SSc}-\mathrm{PAH}^{94}$ over a mean duration of 10 months (range 1 to 18 months). The mean NT-proBNP level in patients without PAH was significantly lower than in those with SSc-PAH $(P=0.0002)$. For every order of magnitude increase in NT-proBNP level in patients with PAH, the risk of death increased 4-fold ( $P=0.002$ for baseline level and $P=0.006$ for follow-up level). Baseline NT-proBNP levels correlated directly with mPAP (r = 0.62; $P<0.0001)$, PVR (r =0.81; $P<0.0001)$, and inversely with 6MWD $(\mathrm{r}=-0.46 ; P<0.0001)$. Plasma NT-proBNP levels also identified differences in functional class among patients with SSc-PAH. The 13 patients (19\%) in WHO functional class II had mean N-TproBNP levels of $325 \pm 388 \mathrm{pg} / \mathrm{mL}$, whereas the 53 patients $(78 \%)$ in $\mathrm{WHO}$ classes III and IV had mean NT-proBNP levels that were 5-fold higher $(1677 \pm 2835 \mathrm{pg} / \mathrm{mL}, P=0.02)$.

The correlation of circulating BNP levels with pulmonary hemodynamics, right heart strain and survival has generated interest in using it as a noninvasive assessment of response

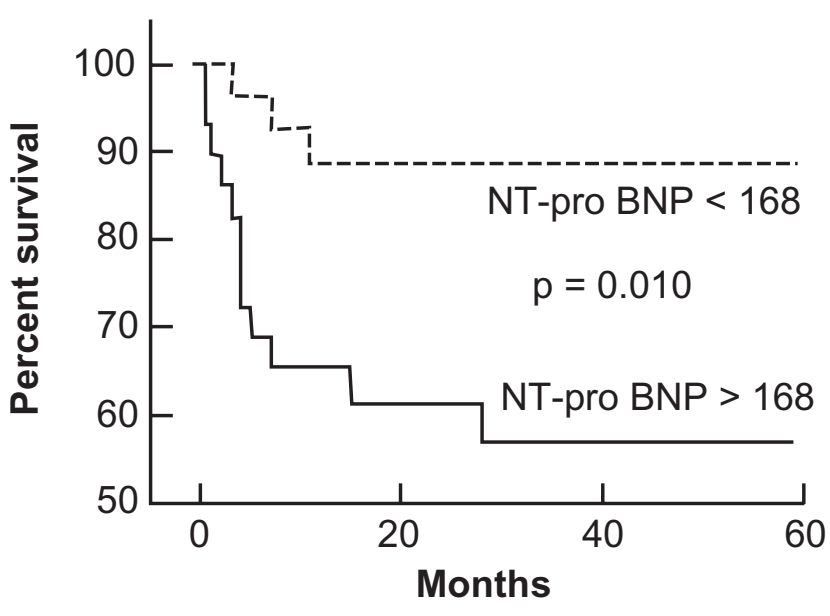

Figure 4 Effect of plasma N-terminal pro-brain natriuretic peptide (NT-proBNP) levels on survival in patients with pulmonary arterial hypertension. Reproduced with permission from Andreassen AK, Wergeland R, Simonsen S, Geiran O, Guevara C, Ueland T. N-terminal pro-B-type natriuretic peptide as an indicator of disease severity in a heterogeneous group of patients with chronic precapillary pulmonary hypertension. Am J Cardiol. 2006;98:528-529. ${ }^{198}$ Copyright (C) 2002 Elsevier. 
to therapy. In an early study of nine patients with IPAH who underwent prostaglandin therapy, ${ }^{87}$ plasma BNP levels fell in conjunction with TPR after a mean follow-up of 35 days (TPR $23 \pm 4$ to $15 \pm 3$ Wood units, $P<0.05$; plasma BNP $315 \pm 120$ to $144 \pm 54 \mathrm{pg} / \mathrm{mL} P<0.05)$. In a larger follow-up study by Nagaya and colleagues, BNP measurements were repeated after 3 months of vasodilator therapy in 49 patients with idiopathic PAH. ${ }^{105}$ Changes in plasma BNP were associated with changes in RV end-diastolic pressure and TPR but not mPAP or right ventricular dimension. During prostacyclin therapy, plasma BNP significantly decreased in survivors but increased in non-survivors. Park and colleagues studied 20 patients with PAH on epoprostenol and similarly found that BNP may help predict those who are refractory to treatment. ${ }^{107}$ Leuchte et al found that BNP levels parallel changes in pulmonary hemodynamics and functional parameters, including 6MWD, in 30 patients with PAH. ${ }^{108}$ Progression of the disease was accompanied by an increase in BNP levels, whereas improvement of pulmonary hemodynamics and functional status was accompanied by a significant decline in plasma BNP concentrations. Findings from studies such as these suggest that serial plasma BNP could be useful in monitoring the efficacy of therapy in PAH patients and this approach is reflected in recent guidelines from the American College of Cardiology that suggest the use of plasma BNP levels in assessing the risk of deterioration in patients with $\mathrm{PAH} .{ }^{109}$ Although one-time measures of circulating BNP may be difficult to interpret, serial BNP testing may provide a non-invasive measure to help identify patients who are failing their current therapeutic regime and predict RV decompensation before it becomes clinically apparent. This is supported by the finding that higher BNP levels at presentation with pulmonary embolism is associated with increased mortality in two recent studies with large cohorts of patients. ${ }^{110,111}$ These findings suggest that in pulmonary embolism at least, BNP can help identify patients with increased right ventricular strain at higher risk for acute decompensation.

\section{Effect of BNP on right ventricle and pulmonary circulation}

In addition to being a biomarker of elevated PAP and right heart failure, BNP has many biologic properties that could be beneficial in combating progressive pulmonary vascular disease. These properties have piqued the interest of investigators and clinicians in BNP as a potential therapeutic target in the management of PAH. Before discussing therapeutic approaches, a review of the current understanding of
BNP effects on the heart and pulmonary circulation is presented.

\section{Effect on PA pressure}

BNP relaxes preconstricted isolated pulmonary arteries and blunts hypoxic pressor responses in isolated perfused rat lungs with a potency similar to that of ANP (Figure 5). ${ }^{112}$ Although circulating BNP levels are an order of magnitude lower than ANP, the percent increases in plasma BNP levels and right heart BNP expression during exposure to chronic hypoxia are similar for both peptides. ${ }^{112}$ These data suggest that BNP, in concert with ANP, may play a role in modulating pulmonary hypertensive responses and protecting the right heart from the development of hypoxic pulmonary hypertension. In one study, BNP was more effective than ANP at blunting pulmonary hypertension in rats exposed to 3 weeks of hypoxia. ${ }^{113}$ Furthermore, mice deficient in NPR-A, the receptor that mediates the pulmonary vasodilator effects of both ANP and BNP develop greater pulmonary hypertension and right ventricular hypertrophy than wild type mice after exposure to chronic hypoxia. ${ }^{14,115}$ These studies suggest that ANP and BNP signaling through NPR-A play important roles in regulating pulmonary vascular tone and in the pathogenesis of hypoxia-induced pulmonary hypertension. Interestingly, chronic hypoxia causes a significant downregulation of NPR-C expression in pulmonary vascular smooth muscle in vitro and a marked decrease in pulmonary clearance of ANP in intact rats. ${ }^{116,117}$ This may represent a compensatory response of the lungs to increase the circulating levels of natriuretic peptides in the pulmonary vasculature and attenuate the effect of hypoxic pulmonary hypertension.

\section{Effect on pulmonary vascular smooth muscle proliferation}

In addition to its vasorelaxant effects, BNP has antiproliferative effects on vascular smooth muscle cells in culture and thus may play a role in inhibiting pulmonary vascular remodeling. ${ }^{118}$ ANP has been shown to inhibit the effect of several growth factors on the proliferation of smooth muscle cells isolated from the systemic vascular bed, however few studies have examined the effect of the natriuretic peptides on inhibition of pulmonary vascular smooth muscle cell proliferation. Arjona et al found that BNP inhibited proliferation of serum stimulated pulmonary vascular smooth muscle cells and increased generation of intracellular cGMP. ${ }^{119}$ In preliminary studies we have shown that ANP inhibits PDGF-induced proliferation of pulmonary vascular smooth muscle cells as well and that this effect is absent in cells isolated from NPR-A knock 

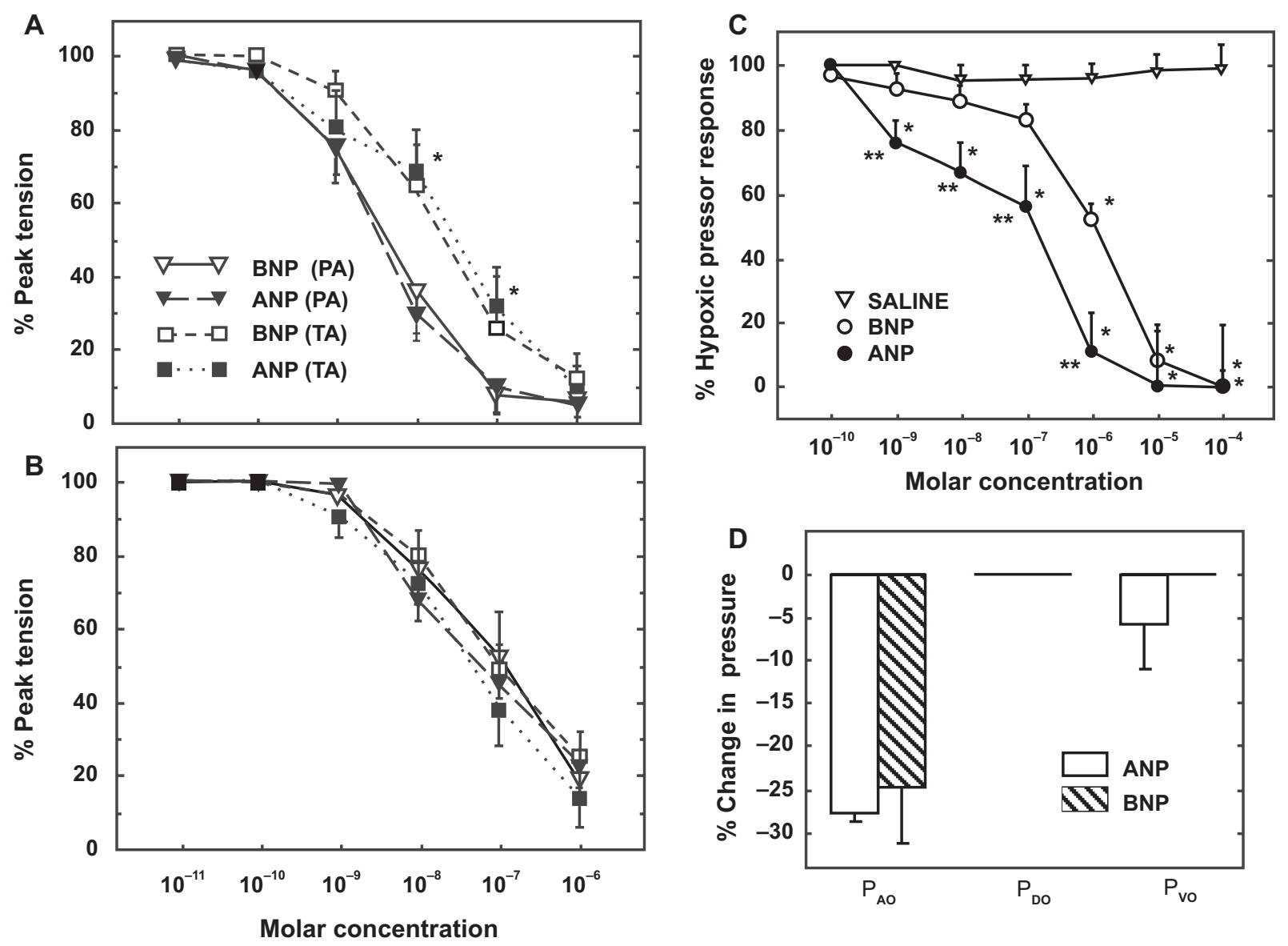

Figure 5 Vasodilator effect of atrial and brain natriuretic peptide (ANP, BNP) on pulmonary arterial rings isolated from normoxic A) and hypoxia-adapted rats B) and preconstricted with phenylephrine. C) Vasodilator effect of ANP and BNP on acute hypoxic pulmonary vasoconstriction in isolated rat lungs. D) Distribution of change in pulmonary vascular resistance following administration of ANP and BNP in isolated rat lungs exposed to acute hypoxia. Pressure in the pulmonary arteries, veins, and capillaries were assessed by occluding the pulmonary artery catheter $\left(\mathrm{P}_{\mathrm{AO}}\right)$, pulmonary venous catheter $\left(\mathrm{P}_{\mathrm{vO}}\right)$ and both catheters (double occlusion, $\left.\mathrm{P}_{\mathrm{DO}}\right)$, respectively. ${ }^{112}$

Abbreviations: PA, pulmonary artery; TA, thoracic aorta.

out mice. ${ }^{120}$ Together, these studies suggest that ANP and BNP are capable of modulating proliferation of pulmonary vascular smooth muscle via signaling through NPR-A and elevation of cGMP. These findings are consistent with reports showing that pulmonary vascular remodeling is reduced in rats given ANP or BNP infusion during exposure to chronic hypoxia $^{113,121}$ and that mice with gene-targeted disruption of ANP or NPR-A have greater pulmonary vascular remodeling under normoxic conditions and after hypoxic exposure than wild-type littermates. ${ }^{114,115,122}$

\section{Effect on right ventricular hypertrophy}

The natriuretic peptide system also plays an important role in inhibiting maladaptive hypertrophic responses in cardiac myocytes. Numerous studies have demonstrated that cardiac hypertrophy in response to a sustained increased in ventricular afterload is associated with a marked increase in ventricular ANP and BNP mRNA expression. This response is seen in both the right and left ventricle in response to a variety of hypertrophic stimuli such as chronic hypoxia, monocrotaline-induced pulmonary hypertension or aortic banding. ${ }^{122-124}$ Initially, this finding was attributed to the activation of a program of fetal genes during hypertrophy of cardiac myocytes. ${ }^{125}$ As a result, increased ventricular expression of ANP and BNP was considered a marker of maladaptive cardiac hypertrophy. However, other studies have shown that the degree of hypertrophy is inversely related to ANP expression and genetic disruption of ANP, BNP or NPR-A results in increased biventricular cardiac mass under baseline conditions and exaggerated hypertrophic responses to aortic banding or chronic hypoxia. ${ }^{14,122,124,125}$ In addition, hearts of mice with disrupted ANP/BNP-NPR-A signaling have increased deposition of collagen and decreased contractility suggesting that the natriuretic peptides play important roles in mediating maladaptive cardiac hypertrophic effects. ${ }^{126}$ 
Although BNP and ANP appear to signal through the same receptor, mice with targeted deletion of BNP exhibit a different phenotype than ANP-deficient mice. Mice without ANP are hypertensive at sexual maturity and this has not been demonstrated in mice without BNP. Thus, gene deletion experiments suggest that ANP and BNP have distinct physiologic effects and that ANP and BNP may play complementary roles in the regulation of cardiovascular homeostasis through NPR-A.

BNP has been shown to inhibit proliferation of cardiac fibroblasts in culture. ${ }^{127}$ This observation was validated in vivo when ventricular pressure overload caused by abdominal aortic banding induced an increase of multi-focal fibrotic lesions in the ventricles in mice lacking BNP, but not in wild-type mice, despite a similar increase in ventricular mass between the two genotypes. ${ }^{128}$ In this study, ventricular fibrosis was associated with a marked increase in expression of angiotensin converting enzyme, transforming growth factor- $\beta 3$ (TGF $\beta 3$ ), and pro- $\alpha 1$ (I) collagen, factors that are implicated in the generation and progression of ventricular fibrosis. ${ }^{128}$ Finally, BNP has been shown to almost completely abolish TGF $\beta$-induced increases in collagen secretion from cardiac fibroblasts. ${ }^{129}$ Taken together, these results indicate that BNP exerts antifibrotic as well as antihypertrophic effects on the heart and plays an important role in mitigating maladaptive cardiac hypertrophic responses.

The mechanism involved in BNP regulation of fibroblasts is unclear. Kapoun et al found that BNP treatment inhibited TGF $\beta$-induced expression of genes related to fibrosis, (collagen 1, fibronectin, CTGF, PAI-1, and TIMP3, myofibroblast conversion (alpha-smooth muscle actin 2 and nonmuscle myosin heavy chain), proliferation (PDGFA, IGF1, FGF18, and IGFBP10), and inflammation (COX2, IL6, TNF $\alpha$-induced protein 6 , and TNF superfamily). ${ }^{129}$ Other studies have found that ANP and BNP modulate the matrix metalloproteinases, enzymes that play important roles in regulating the production of extracellular matrix proteins. ${ }^{129-131}$

It can be difficult to separate the antihypertrophic effect of BNP from its vasorelaxant properties. Studies of BNP and NPR-A knockout mice typically show increases in systemic arterial and pulmonary arterial pressure as well as cardiac hypertrophy, although the hypertrophic effect of disrupted NPR-A signaling has been more pronounced than its effect on arterial pressure. To differentiate the cardiac from the vascular effects of ANP and BNP, Holtwick et al developed mice with conditional, selective deletion of NPR-A in cardiomyocytes mice. ${ }^{120}$ The endocrine, blood pressure- and volumeregulating effects of ANP were found to be preserved in these mice but significant cardiac hypertrophy was still observed. These findings suggest that NPR-A signaling indeed functions as counter-regulatory hypertrophic circuit in the heart under both basal and pressure-overload conditions. ${ }^{132}$ Interestingly, in humans, certain ANP- and BNP-receptor polymorphisms have been associated with left ventricular mass in essential hypertension. ${ }^{133}$ In addition, a deletion in the 5'-flanking region of the gene encoding NPRA has been associated with hypertension and hypertrophy. ${ }^{134}$

\section{Effect on pulmonary endothelial proliferation and apoptosis}

Preservation of endothelial function is critical in combating pulmonary vascular disease.

Recent studies demonstrate that the NO/sGC/cGMP pathway complements natriuretic peptide/pGC/cGMP such that suppression of one pathway decreases the sensitivity of the other. ${ }^{135,136}$ The reciprocal regulation of natriuretic peptides and nitric oxide suggest that natriuretic peptides could play a key role in treating diseases like PAH that are associated with deficiencies in NO production. Interactions between natriuretic peptides and ET-1 may also be important. BNP can directly inhibit ET-1 synthesis as well as functionally antagonize ET-1-induced vasoconstriction and cardiomyocyte hypertrophy. ${ }^{137}$ These molecular interactions may play a significant role in the cardioprotective function of natriuretic peptides in PAH. Furthermore, classic heterologous desensitization of NPR-A, ie, the ability of other cGMP-elevating enzymes to desensitize NPR-A, does not seem to occur. ${ }^{138}$ This supports important reciprocal regulation of vascular tone by natriuretic peptides and $\mathrm{NO}$, which activate the particulate and soluble isoforms of guanylate cyclase, respectively. ${ }^{135,136}$

Impaired apopotosis of pulmonary vascular endothelial cells may play an important role in the pathogenesis of pulmonary arterial hypertension. Tuder et al have proposed that impaired apoptotic responses in pulmonary vascular endothelial cells favors the emergence of apoptosis- resistant endothelial cells leading to uncontrolled proliferation in PAH. ${ }^{4,139,140}$ ANP, BNP and CNP are all capable of inducing apoptosis in cultured rat endothelial cells, ${ }^{141}$ but the extent to which they modify apoptosis under such circumstances has not been fully defined. During ischemia/reperfusion in rodents and humans, $5 \%$ to $30 \%$ of cardiac myocytes in the area at risk undergo apoptosis within 16 hours. ${ }^{142}$ Kato et al reported that ANP significantly inhibits apoptosis in rat cardiac myocytes and that this effect is mediated by the increase in cGMP followed by activation of the 
Akt/PI3K pathway. ${ }^{143}$ Conversely, ANP has been shown to induce cell cycle entry in terminally differentiated chick cardiac myocytes, and to induce apoptosis in a model of neonatal rat cardiac myocytes. ${ }^{144}$ Therefore, it appears that natriuretic peptides can modulate apoptosis in cardiac myocytes as well as endothelial cells, but to what extent this occurs in pulmonary vascular endothelial cells and/or the right ventricle in $\mathrm{PAH}$ is uncertain.

\section{Effect of BNP on inflammation and oxidative stress}

The pathological lesions in IPAH include areas of marked intima remodeling and near complete obliteration by fibrous tissue. Intravascular and perivascular inflammatory infiltrates have also been described, suggesting that vascular inflammation may contribute to the pulmonary vascular remodeling seen in some forms of PAH. BNP has the ability to modulate the production of inflammatory mediators in activated macrophages such as leukotriene $\mathrm{B}_{4}$, prostaglandin $\mathrm{E}_{2}$ and the cytokines (TNF $\alpha, \mathrm{IL}-12$ and IL-10). ${ }^{145}$ Interestingly, NPR-A knockout mice exhibit decreased neutrophil infiltration to cardiac tissue after ischemic injury compared with wild-type mice by decreasing activation of the transcription factor NF- $\kappa \beta .{ }^{146}$

Oxidative stress also contributes to the pathophysiology of inflammation in the cardiovascular system. ${ }^{147}$ Reactive oxygen species are produced in the lung tissue of patients with severe pulmonary hypertension as a consequence of tissue hypoxia ${ }^{148,149}$ or ischemia ${ }^{150}$ or through the activation of inflammatory cascades and increased production of inflammatory cytokines. ${ }^{151,152}$ BNP reduces the production of free radicals, such as reactive oxygen- and nitrogen species from activated macrophages thereby reducing oxidative stress during inflammation. ${ }^{145}$ This may represent another potential mechanism by which BNP could protect against the progression of vascular disease and endothelial dysfunction in PAH.

\section{Potential role for BNP in treatment of $\mathrm{PH}$}

As described above, BNP influences a variety of biologic processes in a manner that has the potential to benefit patients with PAH. Unfortunately, the peptide structure of BNP results in rapid degradation in the gastrointestinal tract following ingestion, making oral delivery challenging. Intravenous infusion of BNP is feasible using recombinant human BNP developed for the treatment of acute decompensated heart failure (nesiritide; Natrecor ${ }^{\circledR}$ ). Inconvenience, expense and potential safety concerns of continuous intravenous infusion are barriers to conducting even small proof of concept clinical trials. Although it should be acknowledged that long-term intravenous infusion has been used successfully for prostacyclin therapy in PAH. Most of the information available on the use of BNP to treat cardiovascular disease derives from clinical trials in congestive heart failure and acute renal failure and a handful of reports of its acute effects on the pulmonary circulation. ${ }^{153,154}$ As a result, there are limited data on the efficacy or safety of BNP for the treatment of PAH.

BNP has biological effects that are similar to those of ANP, but its circulating levels are much lower and in the absence of any physiological derangements, small increases in plasma BNP levels are unlikely to have significant cardiovascular effects. This is supported by most human studies in which physiological doses of BNP given to healthy volunteers have little effect on blood pressure, heart rate, angiotensin II, or aldosterone synthesis. ${ }^{155-160}$ However, at supra-physiological doses, BNP has been shown to have hypotensive and diuretic properties. For example, infusion of pharmacological doses of BNP into normal subjects leads to a rapid and sustained reduction in mean arterial blood pressure. ${ }^{161}$ The fall in blood pressure is not solely a consequence of vasodilation, but also related to reduced stroke volume and intravascular volume. Pharmacologic doses of BNP have also been shown to have an acute pulmonary vasodilator effect in humans. Intravenous infusion of human BNP (10 pmol kg-1 $\left.\mathrm{min}^{-1}\right)$ blunts the acute pulmonary vasoconstrictor response to hypoxia ${ }^{162}$ and reduces PA pressure in patients with cor pulmonale. ${ }^{163}$ These preliminary studies demonstrate that BNP is capable of reducing elevated PAP in some forms of pulmonary vascular disease.

Clinical experience with BNP infusion in patients with PAH is extremely limited. Michaels et al reported the hemodynamic effects of intravenous nesiritide infusion in five patients with precapillary PH. ${ }^{164}$ At 15 and 30 minutes following infusion, there was a decrease in systemic arterial pressure but no change in right-sided heart pressures or $\mathrm{CO}$. Klinger et al found that a 3-hour BNP infusion alone, although well tolerated in adult patients with $\mathrm{PAH}$, had no effect on mPAP or PVR. ${ }^{165}$ However, the combination of sildenafil followed by BNP infusion caused a statistically significant reduction in both parameters that persisted for up to $6 \mathrm{~h}$ after stopping the BNP infusion (Figure 6). The reduction in MPAP with sildenafil plus BNP was at least as great as that seen with any of the other pulmonary vasodilators used in this trial and greater than that observed 1 hour 

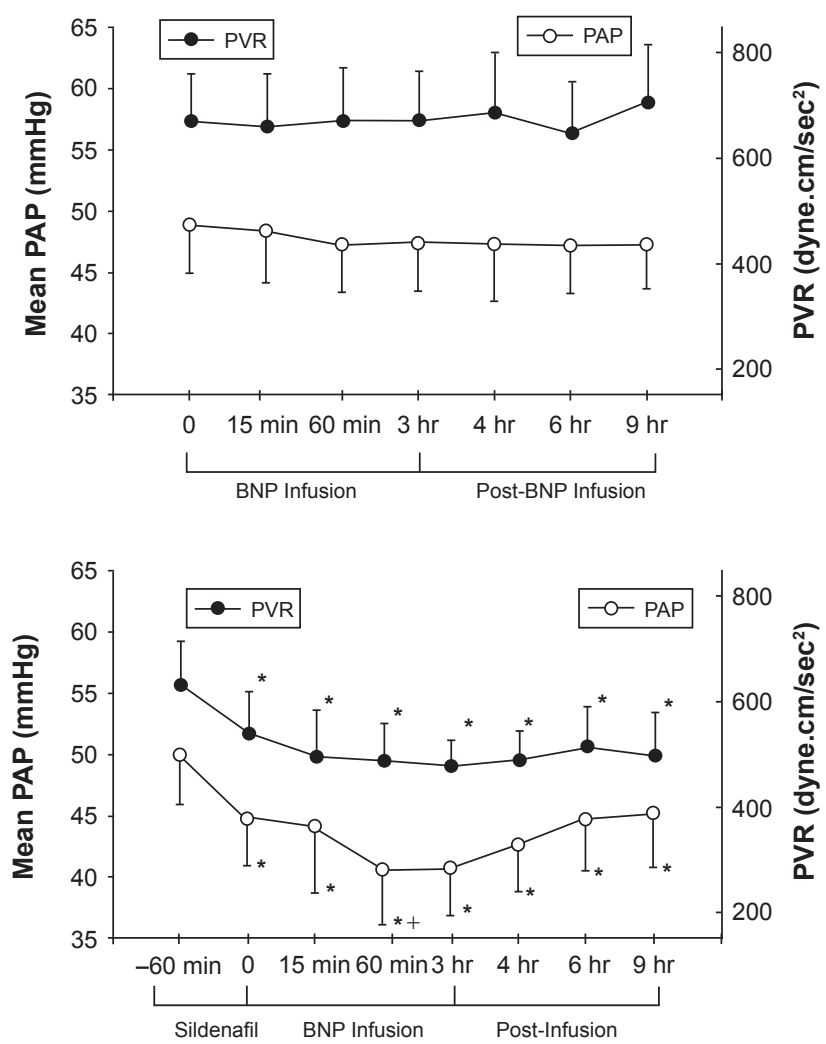

Figure 6 Upper panel: Mean pulmonary arterial pressure (PAP) and pulmonary vascular resistance (PVR) in patients with pulmonary arterial hypertension during a 3-hour infusion of human BNP (nesiritide) and 6 hours after infusion was completed. Lower panel: Effect of BNP infusion on PAP and PVR when given I hour after sildenafil. ${ }^{165}$

after sildenafil alone. Thus, BNP may be able to potentiate the acute vasodilator effects PDE-5 inhibitors.

In addition to its diuretic and acute pulmonary vasodilator effect, the natriuretic peptides generally oppose the actions of angiotensin II, ET-1, and the sympathetic nervous system ${ }^{137}$ and thereby have the potential to improve right ventricular function in patients with PAH. Nesiritide administration leads to a rapid vasodilatory effect and decrease in both right and left ventricular filling pressures and pulmonary capillary wedge pressures ${ }^{166}$ and has been shown to have therapeutic potential in slowing progression of right ventricular dysfunction. ${ }^{167}$

There is increasing recognition that left heart failure may have a relative natriuretic deficient or resistant state. Elevated plasma levels of ANP and BNP are found in patients with congestive heart failure and the magnitude of increase coincides with the severity of heart failure. ${ }^{168-170}$ Studies of early LV dysfunction have demonstrated that natriuretic peptides play an important role in maintaining cardio-renal homeostasis through systemic actions that antagonize volume overload. ${ }^{171}$ Gene deletion studies confirm that NPR-A signaling protects against heart failure induced by volume overload in mice. ${ }^{172}$ However, in severe symptomatic HF, there is sodium and water retention associated with increased systemic vascular resistance and high cardiac filling pressures despite extremely high plasma concentration of immunoreactive ANP and BNP. The discrepancy in plasma levels of natriuretic peptides and their apparent lack of effect on cardiorenal physiology is not clearly understood, but may be due to impaired NP synthesis and release, a down regulation of NPRs at the tissue level, or increased metabolism of cGMP. Animal studies have shown an up-regulation of PDE expression in left ventricular failure, causing impaired cGMP activity despite high stimulation of the guanylyl cyclase-linked NPRs. ${ }^{173}$ Supaporn et al have reported similar increases in PDE-1 and PDE-5 in severe congestive HF in humans. ${ }^{174}$ Abnormal processing of proBNP into less active forms has also been described in congestive heart failure. ${ }^{175}$ Resistance to natriuretic peptides may explain the variable response rate and the need for high doses that characterized the early clinical trials of BNP in congestive heart failure. ${ }^{176-179}$ Recent analyses of clinical trial data of nesiritide have raised concerns about adverse renal effects. ${ }^{180,181}$ The use of nesiritide at the dosages described in the package insert $\left(0.01\right.$ to $\left.0.03 \mu \mathrm{g} \mathrm{kg}^{-1} \mathrm{~min}^{-1}\right)$ was noted to be associated with a dose-dependent increase in serum creatinine. Furthermore, this was exacerbated by systemic hypotension a known adverse effect of nesiritide. This clinical experience needs to be considered in future trials of BNP in pulmonary hypertension.

As discussed previously, BNP has significant antihypertrophic and anti-fibrotic effects on myocardiocytes. It is conceivable that prolonged administration of BNP may mitigate maladaptive hypertrophic responses in the right ventricle. In a small randomized trial of PAH, Wilkins et a ${ }^{182}$ found that patients treated with sildenafil had a significant reduction in right ventricular mass as measured by MRI that was not found in those who received the endothelin receptor antagonist bosentan, despite a similar degree of improvement in 6MWD. Further augmentation of cGMP with the combination of BNP infusion and PDE inhibition may inhibit RV hypertrophy and fibrosis and help to preserve RV function. This idea is supported by the report Khush et al of 10 patients with precapillary $\mathrm{PH}$ that had acute elevations in pulmonary NO and cGMP levels post nesiritide infusion. ${ }^{183}$

To advance the use of BNP as a therapy for PAH, more practical methods will likely be needed to increase plasma BNP levels. Subcutaneous administration of BNP has been used successfully in animal and in clinical studies to increase 
plasma BNP and its second messenger 3',5' -cyclic guanosine monophosphate (cGMP) with subsequent natriuresis and reduction in cardiac filling pressures. ${ }^{184-189}$ In one canine study, ${ }^{188}$ tolerance was not observed following chronic administration of BNP. Development of orally available peptides has long been a challenge, given various barriers to protein absorption and penetration. ${ }^{190}$ Recently, Cataliotti et $\mathrm{al}^{191}$ reported the application of proprietary technology that enabled oral delivery of BNP by covalently attaching short, amphiphilic oligomers to peptides. In normal conscious dogs, this novel oral conjugated human BNP activated cGMP and exerted hypotensive effects. ${ }^{191}$ Recently, Cataliotti et $\mathrm{al}^{192}$ further demonstrated in a canine model of acute hypertension that a more advanced oral conjugated human BNP significantly increased cGMP and lowered MAP. The availability of an orally active NP such as BNP could lead to a much wider application of these peptides. An alternative approach would be to impede degradation of endogenous BNP through NEP inhibition. Neutral endopeptidase is a major enzymatic pathway for the degradation of BNP and also plays a role in kinin and adrenomedulin breakdown. ${ }^{193}$ Inhibition of NEP increases plasma levels of BNP ${ }^{193}$ and has been shown to inhibit hypoxic pulmonary hypertension in rats, ${ }^{194}$ although the mechanism by which this was achieved is not known.

In summary, although few clinical data currently exist, there is evidence to suggest that enhancement of BNP activity, especially in combination with other agents that increase cGMP signaling has the potential to aid in the treatment of PAH. ${ }^{195,196}$ Perhaps most intriguing of the pleiotropic effects of BNP is its antiproliferative/antifibrotic properties and the potential for reversing the maladaptive remodeling associated with $\mathrm{PAH}$.

\section{Summary}

BNP is an integral part of the natriuretic peptide system that functions as a hormonal regulator of cardiovascular homeostasis. Like ANP, it is capable of relaxing pulmonary vascular smooth muscle, especially under condition in which vascular tone is increased. It also shares with ANP diuretic, antimitogenic, antifibrotic and antihypertrophic effects that have the potential to limit pulmonary vascular remodeling and maladaptive hypertrophic responses in the right ventricle. Right ventricular expression and circulating levels of BNP rise markedly in patients with pulmonary hypertension and correlate with severity of disease and mortality. Changes in BNP expression are more prominent in the ventricle than ANP expression, particularly during times of increased ventricular overload. This ventricular response, along with its slower clearance from the circulation appears to be responsible for BNP acting as a better biomarker of ventricular function than ANP. Monitoring of BNP and its precursor NT-ProBNP provides important objective information regarding the ability of the right ventricular to compensate for increased after load as pulmonary vascular disease progresses. The prognostic significance of plasma BNP on survival in pulmonary hypertension is independent of hemodynamic variables and provides the practitioner another tool with which to assess prognosis and response to therapy. Findings from in vitro and intact animal studies suggest that administration of exogenous BNP is capable of blunting pulmonary vasoconstriction and inhibiting the development of pulmonary hypertension, right ventricular hypertrophy and pulmonary vascular remodeling. However, lack of a convenient method for achieving sustained increases in circulating BNP levels has impeded the development of BNP as a therapy for treating pulmonary hypertension. Further study is needed to determine if BNP can potentiate the pulmonary vasodilator effects of phosphodiesterase inhibitors and blunt or reverse maladaptive hypertrophic responses in the right ventricular. New technologies that allow transdermal or oral administration of the natriuretic peptides have the potential to greatly accelerate research into therapeutic use of BNP for cor pulmonale and pulmonary vascular diseases.

\section{Abbreviations}

ANP, atrial natriuretic peptide; BNP, brain natriuretic peptide; CTEPH, chronic thromboembolic pulmonary hypertension; cGMP, dependent protein kinase; cGMP, cyclic guanosine monophosphate; $\mathrm{CNP}, \mathrm{C}$-type natriuretic peptide; CO, cardiac output; ET-1, endothelin-1; FDA, Food and Drug Administration; MPAP, mean pulmonary arterial pressure; NEP, neutral endopeptidase; NO, nitric oxide; NPR-A, natriuretic peptide receptor-A; NPR-B, natriuretic peptide receptor-B; NPR-C, natriuretic peptide receptor-C; NYHA, New York Heart Association; PAH, pulmonary arterial hypertension; PAP, pulmonary arterial pressure; PCWP, pulmonary capillary wedge pressure; PDE, phosphodiesterase; $\mathrm{PH}$, pulmonary hypertension; PKG, PVR, pulmonary vascular resistance; RVSP, right ventricular systolic pressure; RHC, right heart catheterization; SSc-PAH, scleroderma associated PAH; TGF b, transforming growth factor-b; TPR, total pulmonary resistance; TTE, transthoracic echocardiogram; WHO, World Health Organization. 


\section{Disclosures}

The authors declare no conflicts of interest.

\section{References}

1. D'Alonzo GE, et al. Survival in patients with primary pulmonary hypertension. Results from a national prospective registry. Ann Intern Med. 1991;115(5):343-349.

2. Dresdale DT, et al. Primary pulmonary hypertension. I. Clinical and hemodynamic study. Am J Med. 1951;11(6):686-705.

3. Simonneau $\mathrm{G}$, et al. Updated clinical classification of pulmonary hypertension. J Am Coll Cardiol. 2009;54(1 Suppl):S43-S54.

4. Tuder RM, et al. The pathobiology of pulmonary hypertension. Endothelium. Clin Chest Med. 2001;22(3):405-418.

5. Tuder RM, et al. Pathology of pulmonary hypertension. Clin Chest Med. 2007;28(1):23-42, vii.

6. Chan SY, Loscalzo J. Pathogenic mechanisms of pulmonary arterial hypertension. J Mol Cell Cardiol. 2008;44(1):14-30.

7. Granton J, Moric J. Pulmonary vasodilators - treating the right ventricle. Anesthesiol Clin. 2008;26(2):337-353, vii.

8. Aburaya $\mathrm{M}$, et al. Isolation and identification of rat brain natriuretic peptides in cardiac atrium. Biochem Biophys Res Commun. 1989; 163(1):226-232.

9. Aburaya M, et al. Distribution and molecular forms of brain natriuretic peptide in porcine heart and blood. Biochem Biophys Res Commun. 1989;165(2):872-879.

10. Nakao K, et al. Rat brain natriuretic peptide. Isolation from rat heart and tissue distribution. Hypertension. 1990;15(6 Pt 2):774-778.

11. Ogawa Y, et al. Molecular cloning of the complementary DNA and gene that encode mouse brain natriuretic peptide and generation of transgenic mice that overexpress the brain natriuretic peptide gene. J Clin Invest. 1994;93(5):1911-1921.

12. Saito Y, et al. Brain natriuretic peptide is a novel cardiac hormone Biochem Biophys Res Commun. 1989;158(2):360-368.

13. Sudoh T, et al. A new natriuretic peptide in porcine brain. Nature. 1988;332(6159):78-81.

14. Wu CF, Bishopric NH, Pratt RE. Atrial natriuretic peptide induces apoptosis in neonatal rat cardiac myocytes. J Biol Chem. 1997;272(23): 14860-14866.

15. Hino $\mathrm{J}$, et al. Isolation and identification of human brain natriuretic peptides in cardiac atrium. Biochem Biophys Res Commun. 1990;167(2):693-700.

16. Kambayashi $Y$, et al. Isolation and sequence determination of human brain natriuretic peptide in human atrium. FEBS Lett. 1990;259(2): 341-345.

17. Kojima M, et al. Cloning and sequence analysis of cDNA encoding a precursor for rat brain natriuretic peptide. Biochem Biophys Res Commun. 1989;159(3):1420-1426.

18. Porter JG, et al. Cloning of a cDNA encoding porcine brain natriuretic peptide. J Biol Chem. 1989;264(12):6689-66892.

19. Ogawa Y, et al. Natriuretic peptides as cardiac hormones in normotensive and spontaneously hypertensive rats. The ventricle is a major site of synthesis and secretion of brain natriuretic peptide. Circ Res. 1991;69(2): 491-500.

20. Bloch KD, et al. Neonatal atria and ventricles secrete atrial natriuretic factor via tissue-specific secretory pathways. Cell. 1986;47(5): 695-702.

21. Minamino N, et al. Characterization of immunoreactive human C-type natriuretic peptide in brain and heart. Biochem Biophys Res Commun. 1991;179(1):535-542.

22. Nakamura $\mathrm{S}$, et al. Atrial natriuretic peptide and brain natriuretic peptide coexist in the secretory granules of human cardiac myocytes. Am J Hypertens. 1991;4(11):909-912.

23. Hama $\mathrm{N}$, et al. Rapid ventricular induction of brain natriuretic peptide gene expression in experimental acute myocardial infarction. Circulation. 1995;92(6):1558-1564.
24. Nakagawa $\mathrm{O}$, et al. Rapid transcriptional activation and early mRNA turnover of brain natriuretic peptide in cardiocyte hypertrophy. Evidence for brain natriuretic peptide as an "emergency" cardiac hormone against ventricular overload. J Clin Invest. 1995;96(3):1280-1287.

25. D'Souza SP, et al. B-type natriuretic peptide limits infarct size in rat isolated hearts via KATP channel opening. Am J Physiol Heart Circ Physiol. 2003;284(5):H1592-H1600.

26. Toth $\mathrm{M}$, et al. Hypoxia stimulates release of ANP and BNP from perfused rat ventricular myocardium. Am J Physiol. 1994;266(4 Pt 2): H1572-H1580.

27. Wong F, Blendis L. Pathophysiology of sodium retention and ascites formation in cirrhosis: role of atrial natriuretic factor. Semin Liver Dis. 1994;14(1):59-70.

28. Bruneau BG, et al. BNP gene expression is specifically modulated by stretch and ET-1 in a new model of isolated rat atria. Am J Physiol. 1997;273(6 Pt 2):H2678-H2686.

29. Ogawa T, et al. Evidence for load-dependent and load-independent determinants of cardiac natriuretic peptide production. Circulation. 1996;93(11):2059-2067.

30. Bruneau BG, et al. Alpha 1-adrenergic stimulation of isolated rat atria results in discoordinate increases in natriuretic peptide secretion and gene expression and enhances Egr-1 and c-Myc expression. Endocrinology. 1996;137(1):137-143.

31. Potter LR, et al. Natriuretic peptides, their receptors, and cyclic guanosine monophosphate-dependent signaling functions. Endocr Rev. 2006;27(1):47-72.

32. Marumoto $\mathrm{K}$, et al. Increased secretion of atrial and brain natriuretic peptides during acute myocardial ischaemia induced by dynamic exercise in patients with angina pectoris. Clin Sci (Lond). 1995;88(5) $551-556$.

33. Morimoto A, et al. Effect of exercise on plasma adrenomedullin and natriuretic peptide levels in myocardial infarction. Clin Exp Pharmacol Physiol. 1997;24(5):315-320.

34. Nicholson $\mathrm{S}$, et al. Atrial and brain natriuretic peptide response to exercise in patients with ischaemic heart disease. Clin Exp Pharmacol Physiol. 1993;20(7-8):535-540.

35. Nishikimi T, et al. Different secretion patterns of adrenomedullin, brain natriuretic peptide, and atrial natriuretic peptide during exercise in hypertensive and normotensive subjects. Clin Exp Hypertens. 1997;19(4):503-518.

36. Geny B, et al. Enhanced brain natriuretic peptide response to peak exercise in heart transplant recipients. J Appl Physiol. 1998;85(6):2270-2276.

37. Matsumoto A, et al. Effects of exercise on plasma level of brain natriuretic peptide in congestive heart failure with and without left ventricular dysfunction. Am Heart J. 1995;129(1):139-145.

38. Crabtree GR. Generic signals and specific outcomes: signaling through Ca2+, calcineurin, and NF-AT. Cell. 1999;96(5):611-614.

39. Grepin C, et al. A hormone-encoding gene identifies a pathway for cardiac but not skeletal muscle gene transcription. Mol Cell Biol. 1994;14(5):3115-3129.

40. LaPointe MC, et al. Tissue-specific expression of the human brain natriuretic peptide gene in cardiac myocytes. Hypertension. 1996; 27(3 Pt 2):715-722.

41. Thuerauf DJ, et al. Regulation of rat brain natriuretic peptide transcription. A potential role for GATA-related transcription factors in myocardial cell gene expression. J Biol Chem. 1994;269(27):17772-17775.

42. Anand-Srivastava MB, et al. The presence of atrial-natriureticfactor receptors of ANF-R2 subtype in rat platelets. Coupling to adenylate cyclase/cyclic AMP signal-transduction system. Biochem J. 1991;278(Pt 1):211-217.

43. Chinkers M, et al. A membrane form of guanylate cyclase is an atrial natriuretic peptide receptor. Nature. 1989;338(6210):78-83.

44. Gutkowska J, Nemer M. Structure, expression, and function of atrial natriuretic factor in extraatrial tissues. Endocr Rev. 1989;10(4): 519-536.

45. Koesling D. Studying the structure and regulation of soluble guanylyl cyclase. Methods. 1999;19(4):485-493. 
46. Koller KJ, Goeddel DV. Molecular biology of the natriuretic peptides and their receptors. Circulation. 1992;86(4):1081-1088.

47. Schulz S, et al. The primary structure of a plasma membrane guanylate cyclase demonstrates diversity within this new receptor family. Cell. 1989;58(6):1155-1162.

48. Best PJ, et al. Dendroaspis natriuretic peptide relaxes isolated human arteries and veins. Cardiovasc Res. 2002;55(2):375-384.

49. Nakao K, et al. Molecular biology and biochemistry of the natriuretic peptide system. I: Natriuretic peptides. J Hypertens. 1992;10(9):907-912.

50. Schweitz $\mathrm{H}$, et al. A new member of the natriuretic peptide family is present in the venom of the green mamba (Dendroaspis angusticeps). J Biol Chem. 1992;267(20):13928-13932.

51. Suga $S$, et al. Receptor selectivity of natriuretic peptide family, atrial natriuretic peptide, brain natriuretic peptide, and C-type natriuretic peptide. Endocrinology. 1992;130(1):229-239.

52. Schulz $\mathrm{S}$, et al. The primary structure of a plasma membrane guanylate cyclase demonstrates diversity within this new receptor family. Cell. 1989;58(6):1155-1162.

53. Hobbs AJ, Ignarro LJ. Nitric oxide-cyclic GMP signal transduction system. Methods Enzymol. 1996;269:134-148.

54. Feil R, et al. Cyclic GMP-dependent protein kinases and the cardiovascular system: insights from genetically modified mice. Circ Res. 2003;93(10):907-916.

55. Lohmann SM, Fischmeister R, Walter U. Signal transduction by cGMP in heart. Basic Res Cardiol. 1991;86(6):503-514.

56. Lucas KA, et al. Guanylyl cyclases and signaling by cyclic GMP. Pharmacol Rev. 2000;52(3):375-414.

57. Silberbach M, Roberts Jr CT. Natriuretic peptide signalling: molecular and cellular pathways to growth regulation. Cell Signal. 2001;13(4):221-231.

58. Vaandrager AB, de Jonge HR. Signalling by cGMP-dependent protein kinases. Mol Cell Biochem. 1996;157(1-2):23-30.

59. Hamet $\mathrm{P}$, et al. Cyclic GMP as mediator and biological marker of atrial natriuretic factor. J Hypertens Suppl. 1986;4(2):S49-S56.

60. Beavo JA. Cyclic nucleotide phosphodiesterases: functional implications of multiple isoforms. Physiol Rev. 1995;75(4):725-748.

61. D'Souza SP, et al. Autocrine and paracrine actions of natriuretic peptides in the heart. Pharmacol Ther. 2004;101(2):113-129.

62. Essayan DM. Cyclic nucleotide phosphodiesterases. J Allergy Clin Immunol. 2001;108(5):671-680.

63. Mehats $\mathrm{C}$, et al. Cyclic nucleotide phosphodiesterases and their role in endocrine cell signaling. Trends Endocrinol Metab. 2002; 13(1):29-35.

64. Maurice DH, et al. Cyclic nucleotide phosphodiesterase activity, expression, and targeting in cells of the cardiovascular system. Mol Pharmacol. 2003;64(3):533-546.

65. Corbin JD, et al. High lung PDE5: a strong basis for treating pulmonary hypertension with PDE-5 inhibitors. Biochem Biophys Res Commun. 2005;334(3):930-938

66. Maclean MR, et al. Phosphodiesterase isoforms in the pulmonary arterial circulation of the rat: changes in pulmonary hypertension. J Pharmacol Exp Ther. 1997;283(2):619-624.

67. Almeida FA, et al. Clearance function of type $C$ receptors of atrial natriuretic factor in rats. Am J Physiol. 1989;256(2 Pt 2):R469-R475.

68. Bennett BD, et al. Extracellular domain-IgG fusion proteins for three human natriuretic peptide receptors. Hormone pharmacology and application to solid phase screening of synthetic peptide antisera. J Biol Chem. 1991;266(34):23060-23067.

69. Maack T, et al. Functional properties of atrial natriuretic factor receptors. Semin Nephrol. 1993;13(1):50-60.

70. Soleilhac JM, et al. A $94-\mathrm{kDa}$ protein, identified as neutral endopeptidase-24.11, can inactivate atrial natriuretic peptide in the vascular endothelium. Mol Pharmacol. 1992;41(4):609-614.

71. Rademaker MT, et al. Clearance receptors and endopeptidase: equal role in natriuretic peptide metabolism in heart failure. Am J Physiol. 1997;273(5 Pt 2):H2372-H2379.
72. Davidson NC, Struthers AD. Brain natriuretic peptide. J Hypertens. 1994;12(4):329-336.

73. Kishimoto I, et al. Downregulation of C-receptor by natriuretic peptides via ANP-B receptor in vascular smooth muscle cells. Am J Physiol. 1993;265(4 Pt 2):H1373-H1379.

74. Shima M, et al. Intrarenal localization of degradation of atrial natriuretic peptide in isolated glomeruli and cortical nephron segments. Life Sci. 1988;43(4):357-363.

75. Espiner EA, et al. Natriuretic hormones. Endocrinol Metab Clin North Am. 1995;24(3):481-509.

76. Smith MW, et al. Delayed metabolism of human brain natriuretic peptide reflects resistance to neutral endopeptidase. J Endocrinol. 2000;167(2):239-246.

77. Potter LR. Domain analysis of human transmembrane guanylyl cyclase receptors: implications for regulation. Front Biosci. 2005; 10:1205-1220.

78. Mukoyama M, et al. Augmented secretion of brain natriuretic peptide in acute myocardial infarction. Biochem Biophys Res Commun. 1991; 180(1):431-436.

79. Tokola $\mathrm{H}$, et al. Mechanical load-induced alterations in B-type natriuretic peptide gene expression. Can J Physiol Pharmacol. 2001;79(8):646-653.

80. O'Donoghue $\mathrm{M}$, et al. The effects of ejection fraction on $\mathrm{N}$-terminal ProBNP and BNP levels in patients with acute CHF: analysis from the ProBNP Investigation of Dyspnea in the Emergency Department (PRIDE) study. J Card Fail. 2005;11(5 Suppl):S9-S14.

81. Seino Y, et al. Application of NT-proBNP and BNP measurements in cardiac care: a more discerning marker for the detection and evaluation of heart failure. Eur J Heart Fail. 2004;6(3):295-300.

82. Bionda C, et al. Plasma BNP and NT-proBNP assays by automated immunoanalyzers: analytical and clinical study. Ann Clin Lab Sci. 2006;36(3):299-306.

83. Redfield MM, et al. Plasma brain natriuretic peptide concentration: impact of age and gender. J Am Coll Cardiol. 2002;40(5):976-982.

84. Wang TJ, et al. Impact of age and sex on plasma natriuretic peptide levels in healthy adults. Am J Cardiol. 2002;90(3):254-258.

85. Leuchte $\mathrm{HH}$, et al. N-terminal pro-brain natriuretic peptide and renal insufficiency as predictors of mortality in pulmonary hypertension. Chest. 2007;131(2):402-409.

86. Daniels LB, Maisel AS. Natriuretic peptides. J Am Coll Cardiol. 2007;50(25):2357-2368.

87. Nagaya $\mathrm{N}$, et al. Plasma brain natriuretic peptide levels increase in proportion to the extent of right ventricular dysfunction in pulmonary hypertension. J Am Coll Cardiol. 1998;31(1):202-208.

88. Badesch DB, et al. Continuous intravenous epoprostenol for pulmonary hypertension due to the scleroderma spectrum of disease. A randomized, controlled trial. Ann Intern Med. 2000;132(6): 425-434.

89. Battle RW, et al. Prevalence of pulmonary hypertension in limited and diffuse scleroderma. Chest. 1996;110(6):1515-1519.

90. MacGregor AJ, et al. Pulmonary hypertension in systemic sclerosis: risk factors for progression and consequences for survival. Rheumatology (Oxford). 2001;40(4):453-459.

91. Mukerjee D, et al. Significance of plasma N-terminal pro-brain natriuretic peptide in patients with systemic sclerosis-related pulmonary arterial hypertension. Respir Med. 2003;97(11): 1230-1236.

92. Oudiz RJ, et al. Treprostinil, a prostacyclin analogue, in pulmonary arterial hypertension associated with connective tissue disease. Chest. 2004;126(2):420-427.

93. Allanore $\mathrm{Y}$, et al. $\mathrm{N}$-terminal pro-brain natriuretic peptide as a diagnostic marker of early pulmonary artery hypertension in patients with systemic sclerosis and effects of calcium-channel blockers. Arthritis Rheum. 2003;48(12):3503-3508.

94. Williams $\mathrm{MH}$, et al. Role of $\mathrm{N}$-terminal brain natriuretic peptide (N-TproBNP) in scleroderma-associated pulmonary arterial hypertension. Eur Heart J. 2006;27(12):1485-1494. 
95. Mukerjee D, et al. Echocardiography and pulmonary function as screening tests for pulmonary arterial hypertension in systemic sclerosis. Rheumatology (Oxford). 2004;43(4):461-466.

96. Leuchte $\mathrm{HH}$, et al. Clinical significance of brain natriuretic peptide in primary pulmonary hypertension. J Am Coll Cardiol. 2004;43(5):764-770.

97. McQuillan BM, et al. Clinical correlates and reference intervals for pulmonary artery systolic pressure among echocardiographically normal subjects. Circulation. 2001;104(23):2797-2802.

98. Alkotob ML, et al. Reduced exercise capacity and stress-induced pulmonary hypertension in patients with scleroderma. Chest. 2006;130(1):176-181.

99. Grunig E, et al. Stress Doppler echocardiography in relatives of patients with idiopathic and familial pulmonary arterial hypertension: results of a multicenter European analysis of pulmonary artery pressure response to exercise and hypoxia. Circulation. 2009;119(13): 1747-1757.

100. Nagaya $\mathrm{N}$, et al. Plasma brain natriuretic peptide as a noninvasive marker for efficacy of pulmonary thromboendarterectomy. Ann Thorac Surg. 2002;74(1):180-184; discussion 184.

101. Oswald-Mammosser M, et al. Prognostic factors in COPD patients receiving long-term oxygen therapy. Importance of pulmonary artery pressure. Chest. 1995;107(5):1193-1198.

102. Tulevski II, et al. Increased brain natriuretic peptide as a marker for right ventricular dysfunction in acute pulmonary embolism. Thromb Haemost. 2001;86(5):1193-1196.

103. Binder L, et al. N-terminal pro-brain natriuretic peptide or troponin testing followed by echocardiography for risk stratification of acute pulmonary embolism. Circulation. 2005;112(11):1573-1579.

104. Souza R, et al. NT-proBNP as a tool to stratify disease severity in pulmonary arterial hypertension. Respir Med. 2007;101(1): 69-75.

105. Nagaya N, et al. Plasma brain natriuretic peptide as a prognostic indicator in patients with primary pulmonary hypertension. Circulation. 2000;102(8):865-870.

106. Fijalkowska A, et al. Serum N-terminal brain natriuretic peptide as a prognostic parameter in patients with pulmonary hypertension. Chest. 2006;129(5):1313-1321.

107. Park MH, et al. Usefulness of B-type natriuretic peptide as a predictor of treatment outcome in pulmonary arterial hypertension. Congest Heart Fail. 2004;10(5):221-225.

108. Leuchte $\mathrm{HH}$, et al. Characterization of brain natriuretic peptide in long-term follow-up of pulmonary arterial hypertension. Chest. 2005;128(4):2368-2374.

109. McLaughlin VV, et al. ACCF/AHA 2009 expert consensus document on pulmonary hypertension a report of the American College of Cardiology Foundation Task Force on Expert Consensus Documents and the American Heart Association developed in collaboration with the American College of Chest Physicians; American Thoracic Society, Inc.; and the Pulmonary Hypertension Association. J Am Coll Cardiol. 2009;53(17):1573-1619.

110. Kucher N, et al. Prognostic role of brain natriuretic peptide in acute pulmonary embolism. Circulation. 2003;107(20):2545-2547.

111. ten Wolde $\mathrm{M}$, et al. Brain natriuretic peptide as a predictor of adverse outcome in patients with pulmonary embolism. Circulation. 2003;107(16):2082-2084.

112. Hill NS, et al. Brain natriuretic peptide: possible role in the modulation of hypoxic pulmonary hypertension. Am J Physiol. 1994;266(3 Pt 1): L308-L315.

113. Klinger JR, et al. Brain natriuretic peptide inhibits hypoxic pulmonary hypertension in rats. J Appl Physiol. 1998;84(5):1646-1652.

114. Klinger JR, et al. Targeted disruption of the gene for natriuretic peptide receptor-A worsens hypoxia-induced cardiac hypertrophy. Am J Physiol Heart Circ Physiol. 2002;282(1):H58-H65.

115. Zhao L, et al. NPR-A-Deficient mice show increased susceptibility to hypoxia-induced pulmonary hypertension. Circulation. 1999;99(5): $605-607$
116. Klinger JR, et al. C-receptor ligand blocks pulmonary clearance of atrial natriuretic peptide in isolated rat lungs. Proc Soc Exp Biol Med. 1992;201(2):154-158.

117. Sun JZ, et al. Hypoxia reduces atrial natriuretic peptide clearance receptor gene expression in ANP knockout mice. Am J Physiol Lung Cell Mol Physiol. 2000;279(3):L511-L519.

118. Schirger JA, et al. Vascular actions of brain natriuretic peptide: modulation by atherosclerosis and neutral endopeptidase inhibition. $\mathrm{J} \mathrm{Am}$ Coll Cardiol. 2000;35(3):796-801.

119. Arjona AA, et al. Effects of natriuretic peptides on vascular smoothmuscle cells derived from different vascular beds. Gen Pharmacol. 1997;28(3):387-392

120. Klinger JR, Murray JD. Atrial natriuretic peptide inhibits murine pulmonary vascular smooth muscle cell proliferation via natriuretic peptide receptor-A. Proc Am Thor Soc. 2006;3:A857.

121. Jin $\mathrm{H}$, et al. Atrial natriuretic peptide attenuates the development of pulmonary hypertension in rats adapted to chronic hypoxia. J Clin Invest. 1990;85(1):115-120.

122. Klinger JR, et al. Genetic disruption of atrial natriuretic peptide causes pulmonary hypertension in normoxic and hypoxic mice. Am J Physiol. 1999;276(5 Pt 1):L868-L874.

123. Hirata Y, et al. Role of endogenous ANP in sodium excretion in rats with experimental pulmonary hypertension. Am J Physiol. 1992; 262(6 Pt 2):H1684-H1689.

124. Knowles JW, et al. Pressure-independent enhancement of cardiac hypertrophy in natriuretic peptide receptor A-deficient mice. J Clin Invest. 2001;107(8):975-984.

125. Cameron VA, Ellmers LJ. Minireview: natriuretic peptides during development of the fetal heart and circulation. Endocrinology. 2003; 44(6):2191-2194.

126. Oliver PM, et al. Hypertension, cardiac hypertrophy, and sudden death in mice lacking natriuretic peptide receptor A. Proc Natl Acad Sci US A. 1997;94(26):14730-14735.

127. Cao L, Gardner DG. Natriuretic peptides inhibit DNA synthesis in cardiac fibroblasts. Hypertension. 1995;25(2):227-234.

128. Tamura N, et al. Cardiac fibrosis in mice lacking brain natriuretic peptide. Proc Natl Acad Sci U S A. 2000;97(8):4239-4244.

129. Kapoun AM, et al. B-type natriuretic peptide exerts broad functional opposition to transforming growth factor-beta in primary human cardiac fibroblasts: fibrosis, myofibroblast conversion, proliferation, and inflammation. Circ Res. 2004;94(4):453-461.

130. Tsuruda T, et al. Brain natriuretic Peptide is produced in cardiac fibroblasts and induces matrix metalloproteinases. Circ Res. 2002;91(12):1127-1134

131. Wang D, et al. Effects of pressure overload on extracellular matrix expression in the heart of the atrial natriuretic peptide-null mouse. Hypertension. 2003;42(1):88-95.

132. Holtwick R, et al. Pressure-independent cardiac hypertrophy in mice with cardiomyocyte-restricted inactivation of the atrial natriuretic peptide receptor guanylyl cyclase-A. J Clin Invest. 2003;111(9):1399-1407.

133. Rubattu S, et al. Association of atrial natriuretic peptide and type a natriuretic peptide receptor gene polymorphisms with left ventricular mass in human essential hypertension. J Am Coll Cardiol. 2006;48(3):499-505.

134. Nakayama T, et al. Functional deletion mutation of the 5'-flanking region of type A human natriuretic peptide receptor gene and its association with essential hypertension and left ventricular hypertrophy in the Japanese. Circ Res. 2000;86(8):841-845.

135. Hussain MB, et al. Reciprocal regulation of cGMP-mediated vasorelaxation by soluble and particulate guanylate cyclases. Am J Physiol Heart Circ Physiol. 2001;280(3):H1151-H1159.

136. Madhani M, et al. Vascular natriuretic peptide receptor-linked particulate guanylate cyclases are modulated by nitric oxide-cyclic GMP signalling. Br J Pharmacol. 2003;139(7):1289-1296.

137. Sigurdsson A, Swedberg K. The role of neurohormonal activation in chronic heart failure and postmyocardial infarction. Am Heart J. 1996;132(1 Pt 2 Su):229-234. 
138. Fowkes RC, Forrest-Owen W, McArdle CA. C-type natriuretic peptide (CNP) effects in anterior pituitary cell lines: evidence for homologous desensitisation of CNP-stimulated cGMP accumulation in alpha T3-1 gonadotroph-derived cells. J Endocrinol. 2000;166(1):195-203.

139. Sakao S, et al. Initial apoptosis is followed by increased proliferation of apoptosis-resistant endothelial cells. FASEB J. 2005; 19(9):1178-1180.

140. Taraseviciene-Stewart L, et al. Inhibition of the VEGF receptor 2 combined with chronic hypoxia causes cell death-dependent pulmonary endothelial cell proliferation and severe pulmonary hypertension. FASEB J. 2001;15(2):427-438.

141. Suenobu N, et al. Natriuretic peptides and nitric oxide induce endothelial apoptosis via a cGMP-dependent mechanism. Arterioscler Thromb Vasc Biol. 1999;19(1):140-146.

142. Crow MT, et al. The mitochondrial death pathway and cardiac myocyte apoptosis. Circ Res. 2004;95(10):957-970.

143. Kato T, et al. Atrial natriuretic peptide promotes cardiomyocyte survival by cGMP-dependent nuclear accumulation of zyxin and Akt. J Clin Invest. 2005;115(10):2716-2730.

144. Koide M, et al. Atrial natriuretic peptide accelerates proliferation of chick embryonic cardiomyocytes in vitro. Differentiation. 1996;61(1):1-11.

145. Chiurchiu V, et al. Brain Natriuretic Peptide (BNP) regulates the production of inflammatory mediators in human THP-1 macrophages. Regul Pept. 2008;148(1-3):26-32.

146. Izumi $\mathrm{T}$, et al. Blockade of the natriuretic peptide receptor guanylyl cyclase-A inhibits NF-kappaB activation and alleviates myocardial ischemia/reperfusion injury. J Clin Invest. 2001;108(2):203-213.

147. Suematsu N, et al. Oxidative stress mediates tumor necrosis factor-alpha-induced mitochondrial DNA damage and dysfunction in cardiac myocytes. Circulation. 2003;107(10):1418-1423.

148. Chandel NS, et al. Role of oxidants in NF-kappa B activation and TNF-alpha gene transcription induced by hypoxia and endotoxin. J Immunol. 2000;165(2):1013-1021.

149. Hoshikawa Y, et al. Generation of oxidative stress contributes to the development of pulmonary hypertension induced by hypoxia. $J$ Appl Physiol. 2001;90(4):1299-1306.

150. Al-Mehdi AB, et al. Endothelial NADPH oxidase as the source of oxidants in lungs exposed to ischemia or high $\mathrm{K}^{+}$. Circ Res. 1998;83(7):730-737.

151. Humbert $M$, et al. Increased interleukin-1 and interleukin-6 serum concentrations in severe primary pulmonary hypertension. Am J Respir Crit Care Med. 1995;151(5):1628-1631.

152. Tuder RM, Voelkel NF. Pulmonary hypertension and inflammation. J Lab Clin Med. 1998;132(1):16-24.

153. Reynolds EW, et al. Nesiritide for the treatment of pulmonary hypertension and cor pulmonale in an infant. Pediatr Cardiol. 2007; 28(3):229-233.

154. Zakir RM, et al. A comparison of nesiritide vs. epoprostenol in a patient with precapillary pulmonary hypertension due to scleroderma complicated by postcapillary pulmonary hypertension. Congest Heart Fail. 2005;11(6):331-334.

155. Holmes SJ, et al. Renal, endocrine, and hemodynamic effects of human brain natriuretic peptide in normal man. J Clin Endocrinol Metab. 1993;76(1):91-96.

156. Jensen KT, Carstens J, Pedersen EB. Effect of BNP on renal hemodynamics, tubular function and vasoactive hormones in humans. Am J Physiol. 1998;274(1 Pt 2):F63-F72.

157. La Villa G, et al. Cardiovascular and renal effects of low dose brain natriuretic peptide infusion in man. J Clin Endocrinol Metab. 1994;78(5):1166-1171.

158. La Villa $\mathrm{G}$, et al. Acute effects of physiological increments of brain natriuretic peptide in humans. Hypertension. 1995;26(4): 628-633.

159. Lazzeri $\mathrm{C}$, et al. Cardiovascular function during brain natriuretic peptide infusion in man. Cardiology. 1995;86(5):396-401.
160. van der Zander $\mathrm{K}$, et al. Hemodynamic and renal effects of low-dose brain natriuretic peptide infusion in humans: a randomized, placebocontrolled crossover study. Am J Physiol Heart Circ Physiol. 2003;285(3):H1206-H1212.

161. Yoshimura M, et al. Hemodynamic, renal, and hormonal responses to brain natriuretic peptide infusion in patients with congestive heart failure. Circulation. 1991;84(4):1581-1588.

162. Cargill RI, Lipworth BJ. Acute effects of ANP and BNP on hypoxic pulmonary vasoconstriction in humans. Br J Clin Pharmacol. 1995;40(6):585-590.

163. Cargill RI, Lipworth BJ. Atrial natriuretic peptide and brain natriuretic peptide in cor pulmonale. Hemodynamic and endocrine effects. Chest. 1996;110(5):1220-1225.

164. Micheals AD, Madden CK. J Hemodynamic effects of intravenous nesiritide in patients with pulmonary hypertension abstract. $J \mathrm{Am}$ Coll Cardiol. 2004;43(Suppl 5A):192A.

165. Klinger JR, et al. Pulmonary hemodynamic responses to brain natriuretic peptide and sildenafil in patients with pulmonary arterial hypertension. Chest. 2006;129(2):417-425.

166. Colucci WS. Nesiritide for the treatment of decompensated heart failure. J Card Fail. 2001;7(1):92-100.

167. Elkayam U, et al. Nesiritide: a new drug for the treatment of decompensated heart failure. J Cardiovasc Pharmacol Ther. 2002;7(3):181-194.

168. Dickstein K, et al. Pro-atrial natriuretic factor is predictive for the clinical status of patients with heart failure. Tidsskr Nor Laegeforen. 1996;116(13):1562-1566.

169. Gottlieb SS, et al. Prognostic importance of atrial natriuretic peptide in patients with chronic heart failure. J Am Coll Cardiol. 1989; 13(7):1534-1539.

170. Motwani JG, et al. Plasma brain natriuretic peptide as an indicator for angiotensin-converting-enzyme inhibition after myocardial infarction. Lancet. 1993;341(8853):1109-1113.

171. Stevens TL, et al. A functional role for endogenous atrial natriuretic peptide in a canine model of early left ventricular dysfunction. J Clin Invest. 1995;95(3):1101-1108.

172. Nishikimi T, et al. Increased susceptibility to heart failure in response to volume overload in mice lacking natriuretic peptide receptor-A gene. Cardiovasc Res. 2005;66(1):94-103.

173. Forfia PR, et al. Acute phosphodiesterase 5 inhibition mimics hemodynamic effects of B-type natriuretic peptide and potentiates B-type natriuretic peptide effects in failing but not normal canine heart. $\mathrm{J} \mathrm{Am}$ Coll Cardiol. 2007;49(10):1079-1088.

174. Supaporn T, et al. Blunted cGMP response to agonists and enhanced glomerular cyclic 3',5'-nucleotide phosphodiesterase activities in experimental congestive heart failure. Kidney Int. 1996;50(5): 1718-1725.

175. Lam CS, et al. Alternate circulating pro-B-type natriuretic peptide and B-type natriuretic peptide forms in the general population. $J \mathrm{Am}$ Coll Cardiol. 2007;49(11):1193-1202.

176. Burger AJ, et al. Effect of nesiritide (B-type natriuretic peptide) and dobutamine on ventricular arrhythmias in the treatment of patients with acutely decompensated congestive heart failure: the PRECEDENT study. Am Heart J. 2002;144(6):1102-1108.

177. Colucci WS, et al; Intravenous nesiritide, a natriuretic peptide, in the treatment of decompensated congestive heart failure. Nesiritide Study Group. N Engl J Med. 2000;343(4):246-253.

178. Mills RM, et al; Sustained hemodynamic effects of an infusion of nesiritide (human b-type natriuretic peptide) in heart failure: a randomized, double-blind, placebo-controlled clinical trial. Natrecor Study Group. J Am Coll Cardiol. 1999;34(1):155-162.

179. Peacock WFT, et al. Observation unit treatment of heart failure with nesiritide: results from the proaction trial. $J$ Emerg Med. 2005;29(3):243-252.

180. Sackner-Bernstein JD, et al. Short-term risk of death after treatment with nesiritide for decompensated heart failure: a pooled analysis of randomized controlled trials. JAMA. 2005;293(15):1900-1905. 
181. Sackner-Bernstein JD, et al. Risk of worsening renal function with nesiritide in patients with acutely decompensated heart failure. Circulation. 2005;111(12):1487-1491.

182. Wilkins MR, et al. Sildenafil versus Endothelin Receptor Antagonist for Pulmonary Hypertension (SERAPH) study. Am J Respir Crit Care Med. 2005;171(11):1292-1297.

183. Khush KK, et al. Nesiritide acutely increases pulmonary and systemic levels of nitric oxide in patients with pulmonary hypertension. $J$ Card Fail. 2006;12(7):507-513.

184. Chen HH, et al. Subcutaneous administration of brain natriuretic peptide in experimental heart failure. J Am Coll Cardiol. 2000; 36(5):1706-1712.

185. Chen $\mathrm{HH}$, et al. Maximizing the renal cyclic 3'-5'-guanosine monophosphate system with type $\mathrm{V}$ phosphodiesterase inhibition and exogenous natriuretic peptide: a novel strategy to improve renal function in experimental overt heart failure. J Am Soc Nephrol. 2006;17(10):2742-2747.

186. Chen $\mathrm{HH}$, et al. Maximizing the natriuretic peptide system in experimental heart failure: subcutaneous brain natriuretic peptide and acute vasopeptidase inhibition. Circulation. 2002;105(8):999-1003.

187. Chen HH, et al. Subcutaneous administration of the cardiac hormone BNP in symptomatic human heart failure. J Card Fail. 2004;10(2):115-119.

188. Chen $\mathrm{HH}$, et al. Intact acute cardiorenal and humoral responsiveness following chronic subcutaneous administration of the cardiac peptide BNP in experimental heart failure. Eur J Heart Fail. 2006;8(7):681-686.

189. Evgenov OV, et al. NO-independent stimulators and activators of soluble guanylate cyclase: discovery and therapeutic potential. Nat Rev Drug Discov. 2006;5(9):755-768.
190. Delie F, Blanco-Prieto MJ. Polymeric particulates to improve oral bioavailability of peptide drugs. Molecules. 2005;10(1):65-80.

191. Cataliotti A, et al. Oral human brain natriuretic peptide activates cyclic guanosine 3',5'-monophosphate and decreases mean arterial pressure. Circulation. 2005;112(6):836-840.

192. Cataliotti A, et al. Chronic actions of a novel oral B-type natriuretic peptide conjugate in normal dogs and acute actions in angiotensin IImediated hypertension. Circulation. 2008;118(17):1729-1736.

193. Corti R, et al. Vasopeptidase inhibitors: a new therapeutic concept in cardiovascular disease? Circulation. 2001;104(15):1856-1862.

194. Klinger JR, et al. Neutral endopeptidase inhibition attenuates development of hypoxic pulmonary hypertension in rats. J Appl Physiol. 1993;75(4):1615-1623.

195. Ghofrani HA, et al. Oral sildenafil as long-term adjunct therapy to inhaled iloprost in severe pulmonary arterial hypertension. J Am Coll Cardiol. 2003;42(1):158-164.

196. Zhao L, et al. Beneficial effects of phosphodiesterase 5 inhibition in pulmonary hypertension are influenced by natriuretic Peptide activity. Circulation. 2003;107(2):234-237.

197. Barr CS, Rhodes P, Struthers AD. C-type natriuretic peptide. Peptides. 1996;17(7):1243-1251.

198. Andreassen AK, Wergeland R, Simonsen S, Geiran O, Guevara C, Ueland T. N-terminal pro-B-type natriuretic peptide as an indicator of disease severity in a heterogeneous group of patients with chronic precapillary pulmonary hypertension. Am J Cardiol. 2006;98: $528-529$.
Drug Design, Development and Therapy

\section{Publish your work in this journal}

Drug Design, Development and Therapy is an international, peerreviewed open-access journal that spans the spectrum of drug design and development through to clinical applications. Clinical outcomes, patient safety, and programs for the development and effective, safe, and sustained use of medicines are a feature of the journal,

\section{Dovepress}

which has also been accepted for indexing on PubMed Central. The manuscript management system is completely online and includes a very quick and fair peer-review system, which is all easy to use. Visit http://www.dovepress.com/testimonials.php to read real quotes from published authors. 